\begin{tabular}{ccc} 
Coğrafi Bilimler Dergisi & Coğrafi \\
Bilimler & Dergisi \\
\hline & Turkish Journal of Geographical Sciences & e-ISSN:1308-9765 \\
\hline
\end{tabular}

\title{
Kuzey Kıbrıs Türk Cumhuriyeti'nde Su Noksanlığı ve Ĕgilim Analizi
}

\section{Water Deficit and Trend Analysis in the Turkish Republic of Northern Cyprus}

\section{Murat Kale*a}

\begin{tabular}{|c|c|}
\hline Makale Bilgisi & $\ddot{O} z$ \\
\hline Araştırma Makalesi & \multirow{5}{*}{ 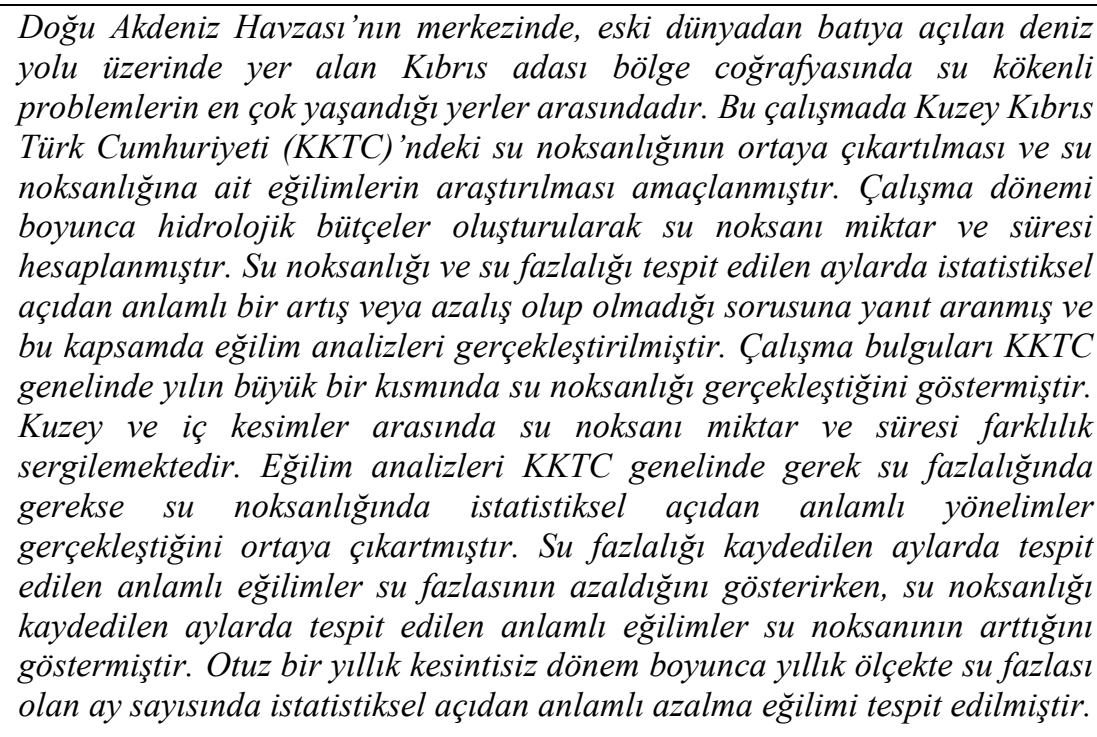 } \\
\hline $\begin{array}{l}\text { DOI: } \\
\text { 10.33688/aucbd } .952128\end{array}$ & \\
\hline $\begin{array}{l}\text { Makale Geçmişi: } \\
\text { Geliş: } 14.06 .2021 \\
\text { Kabul: } 07.10 .2021 \\
\end{array}$ & \\
\hline $\begin{array}{l}\text { Anahtar Kelimeler: } \\
\text { Su bütçesi } \\
\text { Su noksanlığ } \\
\text { Eğilim }\end{array}$ & \\
\hline Kuzey Kıbris & \\
\hline Article Info & Abstract \\
\hline Research Article & \multirow{4}{*}{$\begin{array}{l}\text { The island of Cyprus located in the center of the Eastern Mediterranean Basin, } \\
\text { on the sea route from the old world to the west has huge water-based } \\
\text { problems. This study, it was aimed to reveal the water deficit and trends on } \\
\text { water deficit in the Turkish Republic of Northern Cyprus (KKTC). In this } \\
\text { context, the traces of water deficit were investigated using water budgets. } \\
\text { Water budgets were created and the amount and duration of water deficit were } \\
\text { calculated. Statistically significant trends were investigated in the stations. In } \\
\text { this context, the possible trends on the water deficit and the water surplus } \\
\text { series were investigated separately. The results of the study showed that water } \\
\text { deficit occurs in the KKTC throughout most of the year. The amount and } \\
\text { duration of water deficit differ between the northern and inner parts of KKTC. } \\
\text { Trend analyzes revealed that there are statistically significant trends in both } \\
\text { water deficit and water surplus throughout the KKTC. In addition, a } \\
\text { statistically significant decrease trend was detected in the number of months } \\
\text { that have water deficit on an annual scale. }\end{array}$} \\
\hline $\begin{array}{l}\text { DOI: } \\
\text { 10.33688/aucbd.952128 }\end{array}$ & \\
\hline $\begin{array}{l}\text { Article History: } \\
\text { Received: } 14.06 .2021 \\
\text { Accepted: 07.10.2021 }\end{array}$ & \\
\hline $\begin{array}{l}\text { Keywords: } \\
\text { Water budget } \\
\text { Water deficit } \\
\text { Trend } \\
\text { Northern Cyprus }\end{array}$ & \\
\hline
\end{tabular}

\footnotetext{
*Sorumlu Yazar/Corresponding Author: mmuratkale@gmail.com

${ }^{a}$ Çankırı Karatekin Üniversitesi Edebiyat Fakültesi Coğrafya Bölümü, Çankırı, Türkiye, https://orcid.org/0000-0001-69757069
} 


\section{Giriş}

Dünya, sahip olduğu su kaynaklarının yanı sıra su kaynaklarının yer ve atmosfer sistemleri arasında yer değiştirmesine olanak sağlayan su çevrim sistemi (hidrolojik döngü) sayesinde bilinen tüm gezegenler arasında farklı bir konuma sahiptir. Hidrosferde yer alan toplam su miktarı sabittir. Buna karşın suyun zamanın fonksiyonu olarak alansal dağılımında büyük farklılıklar bulunmaktadır. Ekosistemin canlı üyeleri için vazgeçilmez bir kaynak olan su, dünya üzerindeki yaşamın devamlılığı için anahtar bir role sahiptir. Karasal ekosistemdeki yaşamın neredeyse tamamı tatlı su kaynaklarına farklı şekillerde bağımlıdır. Yer ve atmosfer sistemleri arasında suyun farklı süreçlerin kontrolünde yer değiştirmesine olanak sağlayan hidrolojik döngü aynı zamanda karasal ekosistemdeki tatlı su kaynaklarının oluşumu ve dağılımı üzerinde belirleyicidir (Fetter, 1994). Dinamik bir yapıya sahip olan hidrolojik döngü, yer ve atmosfer alt sistemlerinde meydana gelen değişikliklere son derece duyarlıdır (Chahine, 1992; Huntington, 2006). Alt sistemlerde herhangi bir değişiklik olmadığı sürece belirli bir bölgedeki tatlı suyun varlığı, miktarı ve dağılımında görece uzun dönemler boyunca büyük değişiklikler gerçekleşmesi beklenmezken tersi durumda tatlı su kaynakları üzerinde büyük bir baskı ortaya çıkmaktadır (Chahine, 1992; Hutjes vd., 1998).

Dünya su kaynakları ve iklimi etkileşim halindedir (Türkeş, 2010). Durağan olmayan dünya iklim sistemi, jeolojik devirler boyunca farklı doğal süreçlerin tesirinde değişkenlik göstermiştir (Crowley ve Nort, 1988; Goosse vd., 2010). Atmosfer, dünya iklimini tanımlayan ve denetleyen alt sistemlerin en önemlileri arasında yer alır (Türkeş, 2010; Türkeş, 2012). Hidrolojik döngü, atmosferdeki değişimlerle bir başka ifade ile dünya iklim sistemindeki değişimlerle yakından ilişkilidir (Kundzewicz, 2008). Su kaynakları dağılımı üzerinde belirleyici olan hidrolojik süreçler ise iklimsel değişkenlere bağımlıdır (Cook vd., 2013; Fetter, 1994; Maibach vd., 2014). Atmosfer ve yer sistemleri arasındaki ışınımsal dengenin bozulmasına neden olan her türlü olay söz konusu sistemler arasındaki mevcut enerji dengesini bozarak, dünya iklimi ile birlikte yağış ve sıcaklık değişkenleri üzerinden hidrolojik döngüdeki birçok sürecin etkilenmesine neden olmaktadır (Bates vd., 2008; Fetter, 1994; Türkeş, 2008). 1750 ve 2011 yılları arasında dünya genelinde antropojenik kökenli 1şınımsal dengedeki değişim ortalama olarak 2,3 W/m² (en az 1,1 W/m² en fazla 3,3 W/m²) olarak hesaplanmıştır (IPCC, 2014). Pozitif yönlü ışınımsal zorlama, referans döneme göre atmosferin ısınmakta olduğunu işaret etmektedir. Güncel olarak dünya ortalama sıcaklığındaki artış $1^{\circ} \mathrm{C}$ düzeyine (en az $0,80^{\circ} \mathrm{C}$ en fazla $1,20^{\circ} \mathrm{C}$ ) ulaşarak yükseliş eğilimini sürdürmektedir (Allen vd., 2018). İklim sistemi ve su kaynakları arasındaki etkileşime bağlı olarak, küresel ölçekte gerçekleştirilen sayısal analizler ve iklim tahminleri tatlı su kaynaklarının iklim değişikliğinden güçlü bir şekilde etkileneceğini göstermektedir (Bates vd., 2008; Hagemann vd., 2013; McDonald vd., 2011; Öztürk, 2002).

Yağış, tatlı su kaynaklarının ana girdisidir. Küresel iklim sistemine insanoğlu tarafindan yapılan müdahale hidrolojik döngüde baskı oluşturmakta ve su kaynakları üzerinde farklı bölgelerde farklı hidro-klimatolojik anomalilerin gelişmesine neden olmaktadır (Kundzewicz, 2008; Öztürk vd., 2015; Poschlod, vd., 2020). Hidrolojik döngünün önemli bileşenlerinden biri olan yağışıı alansal dağılım, şiddet ve sıklığında atmosfer sistemindeki değişimlere bağlı olarak farklı bölgelerde farklı eğilimler kaydedilmiştir (Donat vd., 2016; Hosseinzadehtalaei vd., 2020; Madsen vd., 2014; Önol ve Ünal, 2014; Türkeş, 1996; Türkeş vd., 2009). Yirminci yüzyıl boyunca kuzey yarım kürede gerçekleşen yağışların 
yüksek kuzey enlemlerinde artış ve özellikle 1970'lerden itibaren Ekvatora yakın enlemlerde baskın bir azalış eğilimi sergilediği ortaya çıkartılmıştır (Bates vd., 2008). Atmosferdeki sıcaklık değişimine bağlı olarak gerçekleşen negatif yönlü yağış anomalileri dünya genelinde birçok bölgede anlamlı kuraklık eğilimleri gerçekleşmesine (Bates vd., 2008; Danandeh Mehr vd., 2020; Jehanzaib vd., 2020; Padrón vd., 2020, Sağlamoğlu ve Irvem, 2020; Türkeş, 2003; Türkeş, 2020) ve tatlı su kaynaklarına ait su bütçelerinde önemli değişimler yaşanmasına neden olmuştur (Blöschl vd., 2019; Cuthbert vd., 2019; Fan vd., 2013; Grinevskiy vd., 2021; Türkeş, 2020).

Gerek hidro-klimatolojik değişkenlerde tespit edilen değişimler gerekse küresel ölçekli iklim projeksiyonları açısından Akdeniz Havzası, atmosferde kaydedilen pozitif yönlü ışınımsal zorlamadan en çok etkilenen ve etkilenecek bölgeler arasında yer almaktadır. Nemli orta enlemler ile kuru ve sicak kuzey Afrika tropikal kuşağı arasında yer alan Akdeniz Havzası için Hükümetlerarası İklim Değişikliği Panelleri (IPCC)'ne ait farklı tarihlerdeki değerlendirme raporlarının ortak öngörüsü; havza genelinde yirmi birinci yüzyılın sonunda sıcaklık değerinde artış ve yağış miktarında azalış eğilimleri gerçekleşeceğidir (IPCC, 2007; IPCC, 2014). Son dönemde, Akdeniz Havzası'na düşen yağış miktarında anlamlı eğilimler tespit edilmiştir (Kelley vd., 2012; Lionello vd., 2014; Philandras vd., 2011). Özellikle havzanın doğusunda yağış miktarında gerçekleşen negatif yönlü değişimin havzanın orta ve batı kesimlerine göre daha baskın olduğu ortaya çıkartılmıştır (Caloiero vd., 2018; Philandras vd., 2011). Atmosferin 1sınması ve yağış miktarında kaydedilen azalma, Akdeniz Havzası tatlı su kaynakları üzerinde büyük baskı oluşturmaktadır (Iglesias vd., 2007; Sousa vd., 2011). Gelecek projeksiyonları bölgede tatlı su kaynakları üzerindeki baskının azalmayacağını tam tersi şekilde özellikle yirmi birinci yüzyılın sonunda Doğu Akdeniz'de daha da şiddetleneceğini göstermektedir (Chenoweth vd., 2011; IPCC, 2007; IPCC, 2014; Lelieveld vd., 2012). Bu durum özellikle Doğu Akdeniz Havzası tatlı su kaynaklarını kullanan bölge ülkelerinde suya erişim problemleri ortaya çıkartarak tatlı su kaynaklarının stratejik önemini daha da arttıracaktır (Gürsoy ve Jacques, 2014; Yıldız, 2003).

Doğu Akdeniz Havzası'nın merkezinde, eski dünyadan batıya açılan deniz yolu üzerinde yer alan Kıbrıs adası bölge coğrafyasında su kökenli problemlerin en çok yaşandığı yerler arasındadır (Maden, 2013; Şenol, 2020; Zikos vd., 2015). Yaklaşık olarak $9.251 \mathrm{~km}^{2}$ yüz ölçümüyle Akdeniz'in en büyük üçüncü adası olan Kıbrıs, jeopolitik konumu nedeni ile Doğu Akdeniz'de oldukça büyük stratejik öneme sahiptir (Şekil 1). İki egemen devletin yer aldığı adaya ait tatlı su kaynakları akifer sistemleri ve mevsimlik akarsular tarafindan temsil edilir. Akifer sistemleri ve mevsimlik akarsuların beslenimi doğrudan adaya düşen yağışlardan sağlanır. Adanın kuzeyi ve güneyi arasındaki büyük yükselti farkı yağış miktarındaki alansal değişim ve hidrografya üzerinde belirleyicidir (Koday, 1995; Şenol, 2020). Adanın güney batısında $450 \mathrm{~mm}$ olan yağış miktarı Karlıdă̆ (Trodos) aksında 1.100 mm'ye ulaştıktan sonra Mesarya Ovası'nda 350 mm'ye kadar düşerek doğuya doğru azalmaya devam etmekte ve Beşparmak Dağları'nda $500 \mathrm{~mm}$ seviyesine ulaşmaktadır (Katsanos vd., 2016). Ada toplam yenilenebilir su varlığının çok büyük kısmı ada güneyinde yer alan Karlıdağ kütlesinden itibaren gelişir (Christofi vd., 2020). Ada güneyi kuzeyine oranla daha fazla miktarda yağış almakladır. Bu nedenle litolojik ve morfolojik özellikler ada güneyinde kuzeye oranla daha gelişmiş akarsu drenaj ağı oluşturur. Söz konusu durum adanın güneyinde akışa geçen su kütlelerinin depolanmasına görece olanak 
sağlamakta ve adanın güneyini kuzeyine oranla tatlı su kaynakları açısından daha avantajlı konuma getirmektedir. Ada genelinde, Doğu Akdeniz Havzası'nda gerçekleşen 1sınma eğiliminin yaygın etkileri görülmektedir. 1896-1996 yılları arasında sıcaklık değerinde $1{ }^{\circ} \mathrm{C}$ 'ye ulaşan istatistiksel açıdan anlamlı ve pozitif yönlü eğilim tespit edilmiştir (Price vd., 1999). Katsanos vd. (2018), 1961-2010 tarih aralığında şiddetli yağış olaylarının meydana gelme sıklığında artış gerçekleştiğini belirlemiştir. Aynı zamanda 1981-2010 döneminde ada genelinde yağışlı gün sayısında azalma eğilimi tespit edilmiştir (Katsanos vd., 2017). Giannakopoulos vd. (2010), 25 km yatay çözünürlüklü bölgesel iklim modeli kullandıkları çalışmalarında 2021-2050 ve 2071-2100 dönemlerinde adanın daha da 1sınacağı ve yağış miktarının azalacağı bulgularına ulaşmıştır. Zittis vd. (2020), 12 km yatay çözünürlüklü bölgesel iklim modeli çıktıları kullanarak yüzyılın sonuna kadar daha kuru ve daha sıcak iklim koşullarının ada genelinde egemen olacağını açıklamıştır. Farklı projeksiyonların ortak öngörüsü; Mesarya Ovası ve özellikle ada güneydoğusunda sıcaklıkların ada geneline oranla daha yüksek oranda artacağı ve yağış miktarının ada geneline oranla daha yüksek oranda azalacağı yönündedir (Giannakopoulos vd., 2010; Zittis vd., 2020).

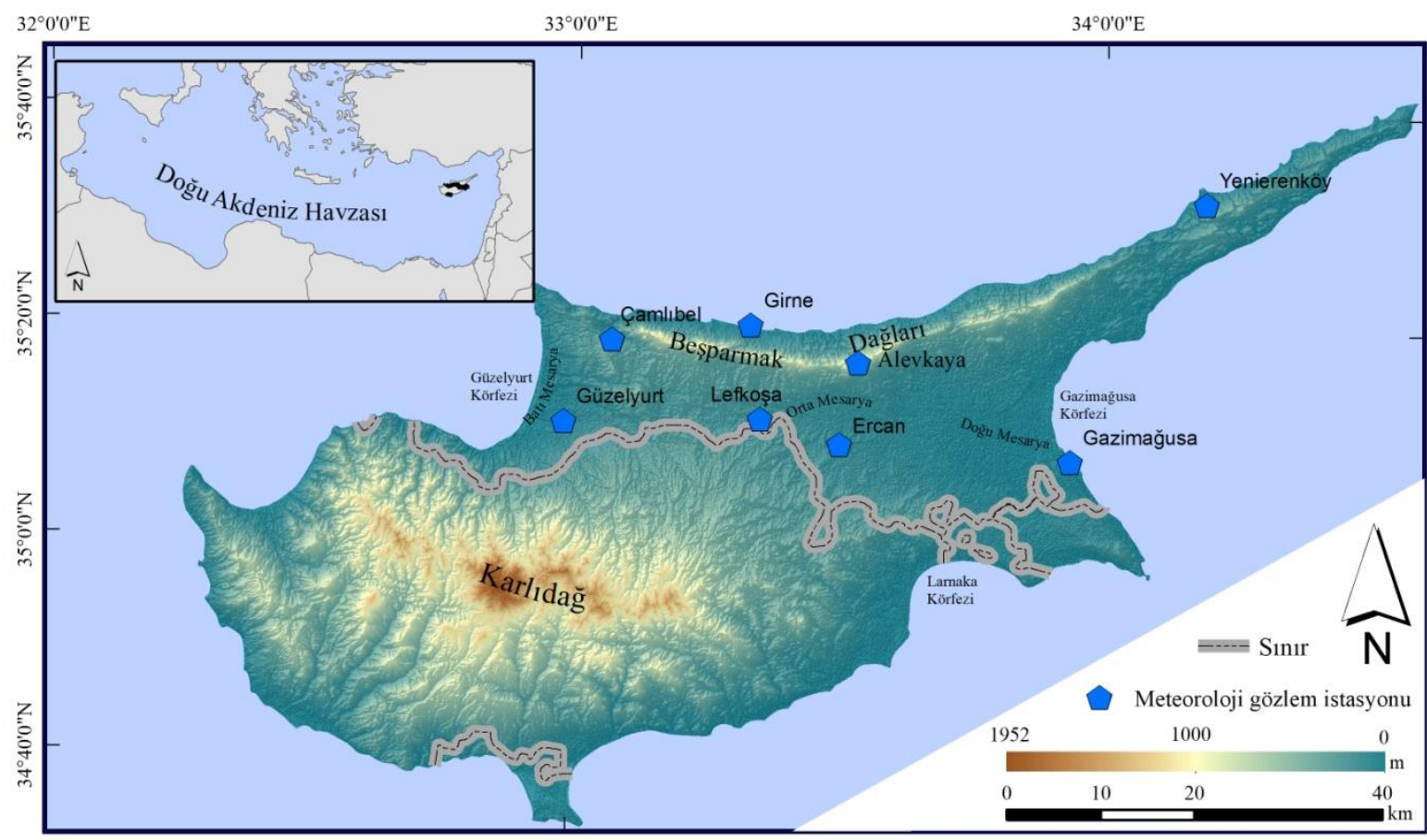

Şekil 1. Kıbris adası

Bu çalışmaya konu olan Kuzey Kıbrıs Türk Cumhuriyeti (KKTC) Falkenmark indisine göre 328 $\mathrm{m}^{3} / \mathrm{y} 1 \mathrm{l}$ kişi başına düşen yenilenebilir su miktarıyla mutlak su kitlığ çeken ülkeler sınır aralığında yer almaktadır (Yılmaz, 2020). 3.354 km² yüz ölçümüne sahip olan KKTC'de daimi akış özelliği sergileyen akarsu bulunmamaktadır (Kutoğlu, 2010). KKTC yüksek oranda yeraltı suyuna bağımlıdır (Koday, 1995; Şenol, 2020). KKTC yeraltı suyu potansiyelinin \%50'sini oluşturan Güzelyurt akiferine ait beslenme alanı dikkate alındığında, akiferin büyük oranda Karlıdağ eteklerine düşen yağıştan itibaren beslenen sınıraşan bir akifer statüsünde olduğu anlaşılır (Phillips Agboola ve Egelioglu, 2012). KKTC güney komşusuna oranla tatlı su kaynakları açısından daha kıt ve yenilenebilir su kaynaklarının beslenme özellikleri dikkate alındığında görece olarak güneye bağımlı bir coğrafyada yer almaktadır. 
KKTC'de gerçekleşen yüksek buharlaşma ve düşük yağış miktarıyla birlikte morfolojik özellikler barajlarda yüksek miktarda su depolanmasına olanak sağlamamaktadır (Maden, 2013). Yeraltı suyuna yüksek oranda bağımlı olan KKTC, sahil akiferlerinde tuzlanma problemi yaşamaktadır (Ergil, 2000). Akifer sistemine ait beslenim özellikleri dikkate alınmadan aşırı su çekimi sonucunda deniz suyunun akifer sistemine girişimi ile gelişen tuzlanma problemi güncel olarak KKTC yenilebilir su kaynakları üzerinde gerek miktar gerekse kalite sorunlarının ortaya çıkmasına neden olmaktadır (Ergil, 2000; Maden, 2013). Kıt tatlı su kaynaklarına sahip olan KKTC evsel kullanım talebini ve sektörel su ihtiyaçlarını karşılamakta güçlük yaşamaktadır (Maden, 2013; Şenol, 2020). Bu kapsamda KKTC'nin ihtiyaç duyduğu suyun temini için farklı projeler geliştirilmiş ve bir kısmı uygulanmıştır. KKTC'ye boru hattı ile su iletim projesinin devreye alınmasından önce 1998-2002 yılları arasında özel tasarlanmış balonlar ile su iletimi gerçekleştirilmiştir. Sahip olduğu tatlı su kaynakları açısından kendi kendine yeter düzeyde olmayan KKTC, atmosferdeki pozitif yönlü ışınımsal zorlamanın etkilerini ciddi şekilde hissetmektedir. Lefkoşa istasyonu 1896-1996 yılları arasında $1{ }^{\circ} \mathrm{C}$ 'ye ulaşan istatistiksel açıdan anlamlı ve pozitif yönlü sıcaklık eğilimine sahne olmuştur (Price vd.,1999). Benzer şekilde, Girne istasyonunda 1967-2003 yılları arasındaki uzun dönem verilerine göre ortalama sıcaklıklarda istatistiksel açıdan anlamlı artış eğilimi tespit edilmiştir (Türkeş ve Sarış, 2007). Payab ve Türker (2018) tarafından 19772013 yılları arasında dokuz istasyona ait veri seti üzerinden gerçekleştirilen çalışmada, istasyonların bir kısmında yağış miktarında anlamı azalış eğilimleri belirlenmiş ve Standart Yağış İndeksi (SPI) ile KKTC'de aşırı kurak sınıf aralığının geliştiği tespit edilmiştir.

Yenilenebilir su kaynakları açısından kendi kendine yeter seviyede olmayan ve mutlak su kitlığı ekseninde su problemi ile mücadele eden KKTC, atmosferdeki pozitif yönlü 1şınımsal zorlamanın yağış değişkeni üzerindeki etkisini net bir şekilde hissetmektedir. Yirmi birinci yüzyılın sonuna kadar gerçekleştirilen farklı projeksiyonlar baskının azalmayacağını öngörmektedir. Akdeniz Havzası'nda olduğu gibi Kuzey Kıbrıs genelinde de suyun varlığı ve su kaynakları yönetiminin önemi gün geçtikçe artmaktadır. Bu kapsamda küresel iklim değişikliğinin KKTC su kaynakları üzerinde kendini ne şekilde gösterdiği ve su bütçesi üzerindeki etkilerinin hangi düzeyde olduğu ise güncel sorunlar arasında yer almaktadır. Kuzey Kıbrıs su kaynakları yönetimi üzerinde söz sahibi olan aktörlerin, karar verme sürecinde küresel iklim değişikliğinin KKTC su kaynakları üzerindeki etkisini değerlendirebilmeleri için su noksanı-fazlası miktar, süre ve eğilimlerindeki değişimler oldukça büyük önem taşımaktadır.

Bu çalışmada KKTC'de gerçekleşen su noksanlığının ortaya çıkartılması ve su noksanlığına ait eğilimlerin araştırılması amaçlanmıştır. Bu kapsamda, su noksanı-fazlası miktar, süre ve eğilimlerindeki değişimlerin saptanması hedeflenmiştir.

\section{Materyal ve Yöntem}

KKTC'de gerçekleşen su noksanlığının ortaya çıkartılmasının ve su noksanlığına ait eğilimlerin araştırılmasının amaçlandığı bu çalışmada uzun dönem su bilançoları (bütçeleri) hesaplanarak su noksanı ve su fazlası sergileyen aylar tespit edilmiştir. Belirlenen aylar için eğilim analizleri gerçekleştirilerek eğilimin varlığı ve başlangıç tarihi araştırılmıştır.

Çalışmada kullanılan veri seti aylık ortalama sıcaklık $\left({ }^{\circ} \mathrm{C}\right)$ ve aylık toplam yağış miktarı $(\mathrm{mm})$ değişkenlerinden oluşmaktadır. 1986-2016 yılları arasındaki otuz bir yıllık kesintisiz döneme ait sekiz 
farklı istasyon kayıtlarını kapsayan veri seti KKTC Meteoroloji Dairesi’nden temin edilmiştir. İstasyon konumları Şekil 1'de ve istasyonlara ait temel bilgiler Çizelge 1'de verilmiştir.

Çizelge 1. Çalışmada kullanılan istasyonlara ait genel bilgiler

\begin{tabular}{|c|c|c|c|c|c|c|}
\hline \multirow{2}{*}{$\mathrm{Ad}$} & \multirow{2}{*}{ Numara } & \multicolumn{2}{|c|}{ Konum } & \multirow{2}{*}{ Yükseklik (m) } & \multicolumn{2}{|c|}{ Zaman serisi } \\
\hline & & Enlem & Boylam & & Başlangıç & Bitiş \\
\hline Alevkaya & 17560 & $35^{\circ} 17^{\prime} 05,47^{\prime \prime} \mathrm{K}$ & $33^{\circ} 32^{\prime} 04,26^{\prime \prime} \mathrm{D}$ & 631 & 1986 & 2016 \\
\hline Çamlıbel & 17570 & $35^{\circ} 18^{\prime} 54,56^{\prime \prime} \mathrm{K}$ & $33^{\circ} 04^{\prime} 12,33^{\prime \prime} \mathrm{D}$ & 271 & 1986 & 2016 \\
\hline Ercan & 17521 & $35^{\circ} 09^{\prime} 10,40^{\prime \prime} \mathrm{K}$ & $33^{\circ} 30^{\prime} 42,49^{\prime \prime} \mathrm{D}$ & 112 & 1986 & 2016 \\
\hline Girne & 17510 & $35^{\circ} 20^{\prime} 27,21^{\prime \prime} \mathrm{K}$ & $33^{\circ} 19^{\prime} 52,19^{\prime \prime} \mathrm{D}$ & 7 & 1986 & 2016 \\
\hline Güzelyurt & 17500 & $35^{\circ} 11^{\prime} 27,21^{\prime \prime} \mathrm{K}$ & $32^{\circ} 58^{\prime} 53,82^{\prime \prime} \mathrm{D}$ & 49 & 1986 & 2016 \\
\hline Lefkoşa & 17515 & $35^{\circ} 12^{\prime} 46,45^{\prime \prime} \mathrm{K}$ & $33^{\circ} 21^{\prime} 07,98^{\prime \prime} \mathrm{D}$ & 133 & 1986 & 2016 \\
\hline Gazimağusa & 17540 & $35^{\circ} 08^{\prime} 07,20^{\prime \prime} \mathrm{K}$ & $33^{\circ} 56^{\prime} 34,38^{\prime \prime} \mathrm{D}$ & 4 & 1986 & 2016 \\
\hline Yenierenköy & 17550 & $35^{\circ} 31^{\prime} 30,32^{\prime \prime} \mathrm{K}$ & $34^{\circ} 10^{\prime} 28,14^{\prime \prime} \mathrm{D}$ & 121 & 1986 & 2016 \\
\hline
\end{tabular}

İklimsel değişkenlerden oluşan zaman serilerinde farklı nedenlerden dolayı oluşabilecek sıçramalar veri setinin güvenilirliğini azaltmaktadır (Demircan vd., 2015; Sneyers, 1990; Türkeş vd., 2009). Siçramaya neden olabilecek iklimsel olmayan herhangi bir kök nedenin veri seti üzerindeki etkisinin asgari düzeyde olduğunu belirlemek için veri setinin güvenilirliği kontrol edilmelidir (Sneyers, 1990). Veri setinin güvenilirliğinin kontrolü için türdeşlik sınamaları literatürde yaygın bir şekilde kullanılmaktadır. Bu çalışmanın temel materyalini oluşturan sıcaklık ve yağış değişkenlerine ait örneklem hacmi hidro-klimatolojik çalışmalardaki asgari süreyi (otuz yıl) kapsamakla birlikte yeterince uzun değildir. Veri setinin niceliksel açıdan alt sınırda olması ve normal dağılım fonksiyonuna uyum sağlamaması nedenlerinden dolayı türdeşlik sınamasında parametrik olmayan yöntemlerin kullanılmasına karar verilmiştir. Türdeşlik sınaması için Kruskal-Wallis (K-W) testi uygulanmıştır. $\mathrm{K}-$ W varyans analizine ait test istatistiği değeri $(X)$ eşitlik 1 yardımı ile hesaplanmaktadır (Sneyers, 1990).

$X=\frac{12}{n(n+1)} \sum_{j=1}^{c} \frac{R_{j}^{2}}{n_{j}}-3(n+1)$

Eşitlikte, $n$; toplam örnek sayısı olmak üzere $n_{j}$; j. örnek hacmini, $R_{j}$; j. örnek için sıra sayıları toplamını ve $c$ ise grup sayısını ifade etmektedir (Sneyers, 1990). Değişkenlere ait türdeşlik analizi 0,05 $(\alpha=0,05)$ anlamlılık seviyesi dikkate alınarak rastgele oluşturulan altı grup için veri seti üzerinden gerçekleştirilmiştir. Beş serbestlik derecesi ve \%95 güven aralığında kritik değer 11,07 olup kritik değerin üzerindeki $\mathrm{K}-\mathrm{W}$ test istatistiği değerleri serinin türdeş olmadığını göstermektedir (Gamgam vd., 2013). Değişkenler için gerçekleştirilen sınama sonuçlarından veri setinde istatistiksel açıdan anlamlı bir sıçramanın olmadığı tespit edilmiştir.

Havza özelinde su bütçesi hesaplamaları; sisteme giren ve sistemi terk eden su miktarına bağlı olarak en basit hali ile eşitlik 2'de verilmiş olan bütçe elemanları yardımı ile yapılır (Fetter, 1994).

$P=R+E t+G \pm I \pm\left(Q_{\text {beslenim }}-Q_{\text {boşalım }}\right)$

Eşitlikte, $P$; yağış, $R$; yüzey akışı, $E t$; buharlaşma ve terleme (evapotranspirasyon), $G$; yeraltı suyu akışı, $I$; sızma (infiltrasyon), $Q_{\text {beslenim }}$; havzaya giren su miktarını ve $Q_{b o s ̧ a l ı m}$; havzadan çıkan su miktarını ifade etmektedir. Bütçe elemanlarının bir kısmı doğrudan ölçüme dayalı iken bir kısmı 
dolaylı olarak ölçüm parametreleri üzerinden hesaplanmaktadır. Buharlaşma ve terleme miktarı bütçe hesaplamalarındaki en önemli bileşenlerden biri olup, potansiyel evapotranspirasyon (Etp) değerinden hesaplanan gerçek evapotranspirasyon (Eta) değeri ile sinırlıdır (Fetter, 1994). Etp'nin hesaplanması için literatürde birçok farklı yöntem bulunmaktadır. Genel olarak en çok kullanılan yöntemler BlaneyCriddle (1950), Penman (1948) ve Thornthwaite (1948) yöntemleridir. Söz konusu yöntemler ortalama hava sıcaklığı, ortalama rüzgâr hızı, bitki yüzeyindeki net radyasyon, yağış miktarı, topraktaki 1s1 akı yoğunluğu, gerçek ve doygun buhar basıncı gibi birbirlerinden farklı girdilere bağımlıdır. Bu çalışmada, hesaplamalar sırasında ihtiyaç duyduğu girdilerin azlığı ve kullanışlılı̆̆ı nedeni ile literatürde yaygın bir şekilde tercih edilen Thornthwaite (1948) yöntemi kullanılarak Etp hesaplamaları gerçekleştirilmiştir.

Kurak yarı-kurak bölgelerde görece iyi sonuçlar veren Thornthwaite (1948) yöntemine göre (Benjamin vd., 2007) Etp değeri eşitlik 3, eşitlik 4 ve eşitlik 5 ile hesaplanmaktadır (Thornthwaite, 1948).

$$
\begin{aligned}
& \text { Etp }=16 \times\left(\frac{10 t}{I}\right)^{\left(6,75 \times 10^{-7} \times I^{3}\right)-\left(7,71 \times 10^{-5} \times I^{2}\right)+\left(1,79 \times 10^{-2} \times I\right)+0,49239} x F(\gamma) \\
& I=\sum_{1}^{12} i \\
& i=\left(\frac{t}{5}\right)^{1,514}
\end{aligned}
$$

Eşitliklerde, Etp; potansiyel evapotranspirasyon, $t$; aylık ortalama sicaklık, $I$; yıllık termal indis, $i$; aylık termal indis ve $F(\gamma)$ aya bağlı enlem düzeltme katsayısını ifade etmektedir.

Bu çalışmada, hesaplanan Etp değerinden itibaren hidrolojik bütçe oluşturularak su noksanı ve su fazlası olan aylar veri setini oluşturan sekiz istasyon için ayrı ayrı belirlenmiştir. İstasyonlara ait su noksanlığı ve su fazlalığı sergileyen ayların belirlenmesinden itibaren KKTC genelinde su noksanlığı ve su fazlalığı yaşanan aylar ortaya çıkartılmıştır.

Kuzey Kıbrıs genelinde yıllara göre su fazlası ve su noksanı olan ay sayıları ile su noksanlığı ve su fazlalığ 1 tespit edilen aylarda istatistiksel açıdan anlamlı bir artış veya azalış olup olmadığı sorusuna yanıt aranmış ve bu kapsamda eğilim analizleri gerçekleştirilmiştir. Eğilim analizleri için gerekli olan veri seti, çalışma dönemi boyunca her bir su yılı için istasyonlara ait su bilançolarının ayrı ayrı hazırlanması ile üretilmiştir. Bu kapsamda, iki yüz kırk sekiz su bilançosu hazırlanmıştır.

$\mathrm{Bu}$ çalışmada gerçekleştirilen eğilim analizleri için parametrik olmayan yöntemlerden biri olan Mann-Kendall (M-K) sıra korelasyon test istatistiği kullanılmıştır. Tüm parametrik olmayan yöntemlerde olduğu gibi M-K sıra korelasyon test istatistiği hesaplamalarında homojenlik, normallik ve bağımsızlık şartları aranmak zorunda değildir. Yöntem homojenlik, normallik ve bağımsızlık şartlarının karşılanmasına gereksinim duymadığı, bir eğilim olması halinde grafiksel olarak eğilimin başlangıç noktasının belirlenebilmesine olanak sağladığı ve hidro-klimatolojik veri setlerinin analizinde literatürde güvenilir sonuçlar vererek sıklıkla kullanıldığı için bu çalışmada tercih edilmiştir.

$\mathrm{M}-\mathrm{K}$ sıra korelasyon test istatistiği, zaman serisinde yer alan her bir verinin sayısal değerinin büyüklüğü $\left(x_{i}\right)$ yerine söz konusu verinin sırasını $\left(y_{i}\right)$ dikkate almaktadır. Yöntem eğilimin istatistiksel momentinin belirlenmesini sağlayarak eğer eğilim var ise yönü hakkında bilgi vermektedir (Türkeş, 1996; Türkeş vd., 2002). M-K sıra korelasyon testinde, her bir $y_{i}$ değeri için ( $i>j$ koşulunu sağlaması 
şartıyla) kendisinden önce gelen veri kümesi elemanlarının $\left(y_{j}\right)$ sayısının $\left(n_{i}\right)$ bulunmasından itibaren test istatistiği değeri $(t)$ elde edilir. Orijinal veri setine ait test istatistiği eşitlik 6 kullanılarak hesaplanır (Sneyers, 1990).

$$
t=\sum_{i=1}^{n} n_{i}
$$

M-K sıra korelasyon test istatistiği eşitlik 7 yardımı ile bulunur (Sneyers, 1990).

$$
u(t)=\frac{t-E(t)}{\sqrt{\text { vart }}}
$$

Burada, $u(t) ; \mathrm{M}-\mathrm{K}$ sıra korelasyon test istatistiği değeri, $t$; test istatistik değeri; $E(t)$; test istatistiği ortalamasını ve $\operatorname{var}(t)$; test istatistiği varyansını ifade eder (Sneyers, 1990; Türkeş, 1996). Test istatistiğine ait ortalama ve varyans değerleri ise sırasıyla eşitlik 8 ve 9 yardımı ile hesaplanır (Sneyers, 1990).

$$
\begin{aligned}
& E(t)=\frac{n(n-1)}{4} \\
& \operatorname{var}(t)=\frac{n(n-1)(2 n+5)}{72}
\end{aligned}
$$

Elde edilen $u(t)$ değerinin sıfıra yaklaşması zamana göre eğilim olmadığı hipotezini doğrular (Sneyers, 1990). $u(t)$ değerinin sıfır değerinden büyük olması ise bir eğilimin olduğu hipotezini destekler. Sıfırdan büyük olan $u(t)$ değeri artan bir eğilimin, sıfirdan küçük olan $u(t)$ değeri ise azalan bir eğilimin göstergesidir (Sneyers, 1990). Grafiksel olarak M-K sıra korelasyon test istatistiği eğilimin başlangıcını sunar. Test istatistiği $u(t)$ ve geriye doğru test istatistiği $u^{\prime}(t)$, eğilimin başladığı yerde birbirine yaklaşır, birbirlerini keser ve daha sonra birbirlerinden uzaklaşır. Eğer herhangi bir eğilim yoksa $u(t)$ ve $u^{\prime}(t)$ birbirlerine defalarca yaklaşarak uzaklaşan yakın bir salınım geometrisi çizer. $u(t)$ ve $u^{\prime}(t)$ kesişim noktası eğilimin başlangıç tarihini verir (Sneyers, 1990).

\section{Bulgular ve Tartışma}

Thornthwaite (1948) yöntemine göre istasyon bazlı olarak hesaplanan uzun dönem (1986-2016) su bilançolarının grafiksel gösterimi Şekil 2'de verilmiştir.

Alevkaya istasyonunda; ocak, şubat, mart ve aralık aylarında kaydedilen yağış miktarının Etp değerinden fazla olduğu tespit edilerek bu aylar su fazlası olan aylar olarak belirlenmiştir. Alevkaya istasyonu için haziran, temmuz, ağustos, eylül ve ekim aylarında ise hem kaydedilen yağış miktarının Etp değerinden düşük olduğu hem de teorik olarak öngörülen depo su miktarının Etp ihtiyacını karşılamadığı tespit edilerek bu aylar su noksanı olan aylar olarak belirlenmiştir. En yükssek miktarda su fazlasının kaydedildiği ay olan ocak ayı ile en yüksek miktarda su noksanının kaydedildiği ay olan temmuz ayı dikkate alındığında; su noksanının su fazlasından 2,43 kat yüksek gerçekleştiği belirlenmiştir. Alevkaya istasyonu uzun dönem su bütçesine göre yılın \%41,66'sinda su noksanlığı geliştiği bulgusuna ulaşılmıştır. 

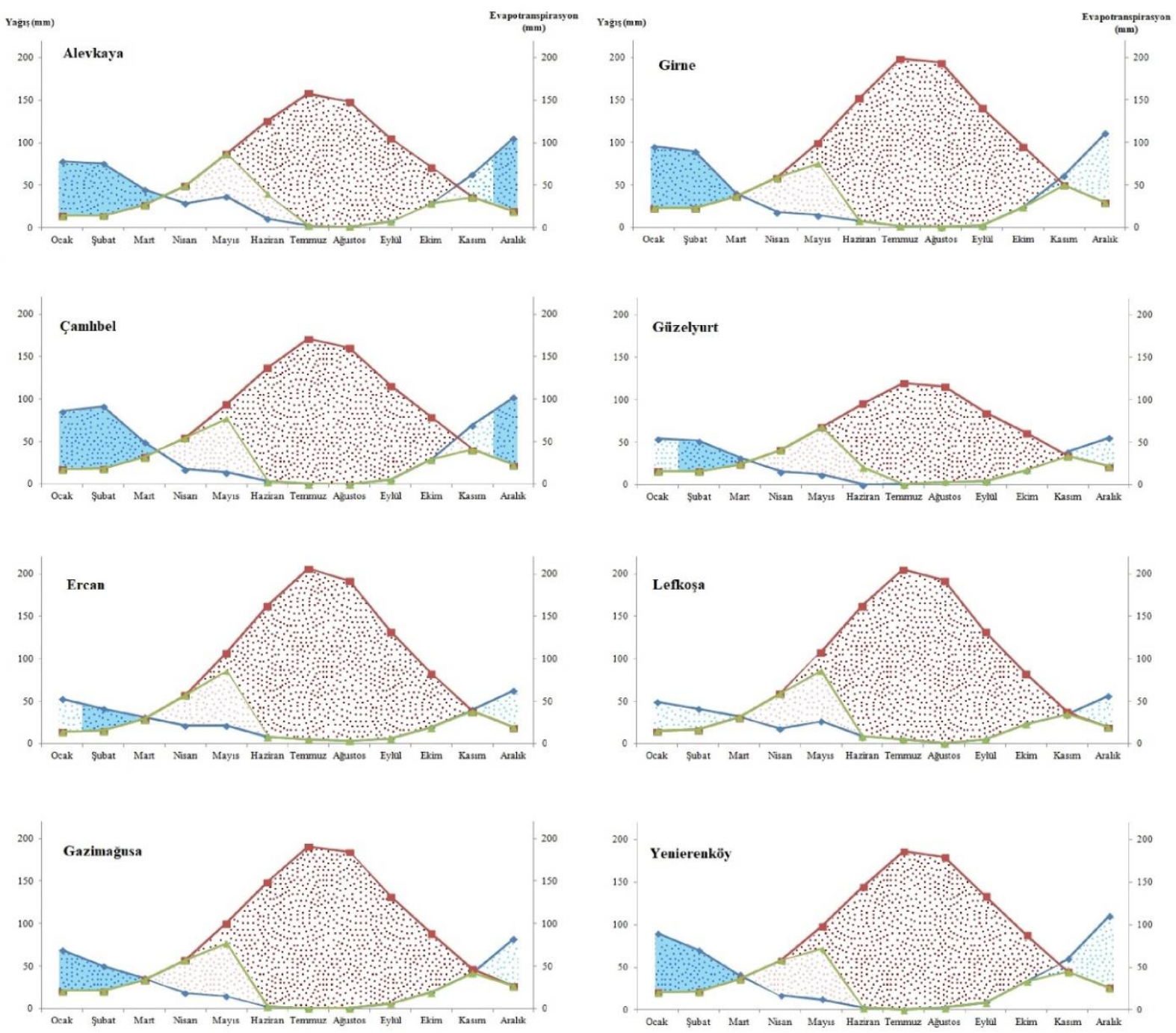

$\leftarrow$ Yağıs̆ (p)

Potansiyel evapotranspirasyon (Etp)

$\mp$ Gerçek evapotranspirasyon (Eta)
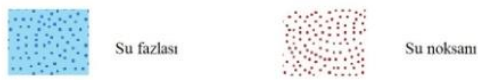

Şekil 2. Thornthwaite (1948) yöntemine göre istasyonlara ait su bilançolarının grafiksel gösterimi (1986-2016)

Çamlıbel istasyonunda; ocak, şubat, mart ve aralık aylarında kaydedilen yağış miktarının Etp değerinden fazla olduğu tespit edilerek bu aylar su fazlası olan aylar olarak belirlenmiştir. Çamlıbel istasyonu için mayıs, haziran, temmuz, ağustos, eylül ve ekim aylarında ise hem kaydedilen yağış miktarının Etp değerinden düşük olduğu hem de teorik olarak öngörülen depo su miktarının Etp ihtiyacını karşılamadığı tespit edilerek bu aylar su noksanı olan aylar olarak belirlenmiştir. En yüksek miktarda su fazlasının kaydedildiği ay olan şubat ayı ile en yüksek miktarda su noksanının kaydedildiği ay olan temmuz ayı dikkate alındığında; su noksanının su fazlasından 2,34 kat yüksek gerçekleştiği belirlenmiştir. Çamlıbel istasyonu uzun dönem su bütçesine göre yılın \%50'sinde su noksanlığı gerçekleştiği belirlenmiştir. 
Ercan istasyonunda; şubat ve mart aylarında kaydedilen yağış miktarının Etp değerinden fazla olduğu tespit edilerek bu aylar su fazlası olan aylar olarak belirlenmiştir. Ercan istasyonu için mayıs, haziran, temmuz, ağustos, eylül ve ekim aylarında ise hem kaydedilen yağış miktarının Etp değerinden düşük olduğu hem de teorik olarak öngörülen depo su miktarının Etp ihtiyacını karşılamadığı tespit edilerek bu aylar su noksanı olan aylar olarak belirlenmiştir. En yüksek miktarda su fazlasının kaydedildiği ay olan şubat ayı ile en yüksek miktarda su noksanının kaydedildiği ay olan temmuz ayı dikkate alındığında; su noksanının su fazlasından 25,35 kat yüksek gerçekleştiği belirlenmiştir. Ercan istasyonu uzun dönem su bütçesine göre yılın \%50'sinde su noksanlığı geliştiği bulgusuna ulaş1lmıştır.

Gazimağusa istasyonunda; ocak, şubat ve mart aylarında kaydedilen yağış miktarının Etp değerinden fazla olduğu tespit edilerek bu aylar su fazlası olan aylar olarak belirlenmiştir. Gazimağusa istasyonu için mayıs, haziran, temmuz, ağustos, eylül, ekim ve kasım aylarında ise hem kaydedilen yağış miktarının Etp değerinden düşük olduğu hem de teorik olarak öngörülen depo su miktarının Etp ihtiyacını karşılamadığı tespit edilerek bu aylar su noksanı olan aylar olarak belirlenmiştir. En yüksek miktarda su fazlasının kaydedildiği ay olan ocak ayı ile en yüksek miktarda su noksanının kaydedildiği ay olan temmuz ayı dikkate alındığında; su noksanının su fazlasından 4 kat yüksek gerçekleştiği belirlenmiştir. Gazimağusa istasyonu uzun dönem su bütçesine göre y1lın \%58,33'ünde su noksanlığ1 gerçekleştiği belirlenmiştir.

Girne istasyonunda; ocak, şubat ve mart aylarında kaydedilen yağış miktarının Etp değerinden fazla olduğu tespit edilerek bu aylar su fazlası olan aylar olarak belirlenmiştir. Girne istasyonu için mayıs, haziran, temmuz, ağustos, eylül ve ekim aylarında ise hem kaydedilen yağış miktarının Etp değerinden düşük olduğu hem de teorik olarak öngörülen depo su miktarının Etp ihtiyacını karşılamadığı tespit edilerek bu aylar su noksanı olan aylar olarak belirlenmiştir. En yüksek miktarda su fazlasının kaydedildiği ay olan ocak ayı ile en yüksek miktarda su noksanının kaydedildiği ay olan temmuz ayı dikkate alındığında; su noksanının su fazlasından 2,71 kat yüksek gerçekleştiği belirlenmiştir. Girne istasyonu uzun dönem su bütçesine göre yılın \%50'sinde su noksanlığı geliştiği bulgusuna ulaşılmıştır.

Güzelyurt istasyonunda; şubat ve mart aylarında kaydedilen yağış miktarının Etp değerinden fazla olduğu tespit edilerek bu aylar su fazlası olan aylar olarak belirlenmiştir. Güzelyurt istasyonu için haziran, temmuz, ağustos, eylül ve ekim aylarında ise hem kaydedilen yağış miktarının Etp değerinden düşük olduğu hem de teorik olarak öngörülen depo su miktarının Etp ihtiyacını karşılamadığı tespit edilerek bu aylar su noksanı olan aylar olarak belirlenmiştir. En yüksek miktarda su fazlasının kaydedildiği ay olan şubat ayı ile en yüksek miktarda su noksanının kaydedildiği ay olan temmuz ayı dikkate alındığında; su noksanının su fazlasından 9,37 kat yüksek gerçekleştiği belirlenmiştir. Güzelyurt istasyonu uzun dönem su bütçesine göre yılın \%41,66'sında su noksanlığı gerçekleştiği belirlenmiştir.

Lefkoşa istasyonunda; su fazlası olan herhangi bir ayın olmadığı belirlenmiştir. Lefkoşa istasyonu için mayıs, haziran, temmuz, ağustos, eylül, ekim ve kasım aylarında ise hem kaydedilen yağış miktarının Etp değerinden düşük olduğu hem de teorik olarak öngörülen depo su miktarının Etp ihtiyacını karşılamadığı tespit edilerek bu aylar su noksanı olan aylar olarak belirlenmiştir. Lefkoşa 
istasyonu uzun dönem su bütçesine göre y1lın $\% 58,33$ 'ünde su noksanlığı geliştiği bulgusuna ulaşılmıştır.

Yenierenköy istasyonunda; ocak, şubat ve mart aylarında kaydedilen yağış miktarının Etp değerinden fazla olduğu tespit edilerek bu aylar su fazlası olan aylar olarak belirlenmiştir. Yenierenköy istasyonu için mayıs, haziran, temmuz, ağustos, eylül ve ekim aylarında ise hem kaydedilen yağış miktarının Etp değerinden düşük olduğu hem de teorik olarak öngörülen depo su miktarının Etp ihtiyacını karşılamadığı tespit edilerek bu aylar su noksanı olan aylar olarak belirlenmiştir. En yüksek miktarda su fazlasının kaydedildiği ay olan ocak ayı ile en yüksek miktarda su noksanının kaydedildiği ay olan temmuz ayı dikkate alındığında; su noksanının su fazlasından 2,70 kat yüksek gerçekleştiği belirlenmiştir. Yenierenköy istasyonunu uzun dönem su bilançosuna göre yılın \%50'sinde su noksanlığı gerçekleştiğini belirlenmiştir.

1986-2016 tarihleri arasındaki otuz bir yıllık kesintisiz dönem için istasyonlara ait uzun dönem su bilançoları dikkate alındığında KKTC genelinde su fazlalığı gerçekleşen ayların ocak, şubat ve mart aylarına; su noksanlığı gerçekleşen ayların ise mayıs, haziran, temmuz, ağustos, eylül ve ekim aylarına kümelendiği bulgusuna ulaşılmıştır. Aynı dönemde KKTC kuzeyinde yer alan istasyonlarda su fazlalığı tespit edilen ay sayısının diğer istasyonlara göre daha fazla olduğu ve su noksanı miktar ve süresinin iç kesimlerde yer alan istasyonlarda çok daha yüksek olduğu belirlenmiştir. Bu kapsamda, Lefkoşa istasyonu hiç su fazlası olmaması, en yüksek miktarda su noksanına (760 mm/y1l) sahip istasyonlardan biri olması ve toplam rasat süresi içerisinde en fazla süre $(\% 58,33)$ su noksanlığ 1 tespit edilen istasyon olması nedenleri ile diğer tüm istasyonlardan ayrılmaktadır. Hiçbir istasyonda gerçekleşen su fazlasının miktarsal olarak aynı istasyonda gerçekleşen su noksanından büyük olmadığ 1 ve istasyonların yılın çok büyük bir döneminde su noksanlığı ile karşı karşıya oldukları tespit edilmiştir. Kuzey Kıbrıs genelinde su fazlalığı sergileyen aylar içerisinde en yüksek miktarda su fazlası ile şubat ayının ön plana çıktığı belirlenmiştir. Buna karşın, su noksanlığı sergileyen aylar içerisinde ise en yüksek miktarda su noksanı ile temmuz ayının ön plana çıktığı bulgusuna ulaşılmıştır.

Ters Mesafe Ağırlıklı Enterpolasyon (IDW) yöntemi kullanılarak oluşturulan su noksanı ve fazlasının aylık olarak KKTC genelindeki alansal dağılımı Şekil 3'de verilmiştir. Ocak ve şubat ayları Kuzey Kıbrıs genelinde su fazlasının yüksek düzeyde gerçekleştiği aylardır. Su fazlasının alansal dağılımında Kuzey Kıbrıs’ın kuzey ve iç bölgeleri arasında büyük farklılık bulunduğu tespit edilmiştir (Şekil 3). KKTC'nin kuzeyinde yer alan ve ülkenin en büyük yükseltisini oluşturan Beşparmak Dağları (1.024 m) boyunca, Çamlıbel-Yenierenköy aksında su fazlası en yüksek seviyeye ulaşmaktadır. Buna karşın, ocak ve şubat aylarında Mesarya genelinde ve özellikle Mesarya'nın batı kısmında (Güzelyurt Ovası) yer alan Güzelyurt ve yakın çevresi ile Mesarya'nın orta kısmında (Orta Mesarya Ovası) yer alan Lefkoşa ve yakın çevresinde su fazlasının olmadığı veya oldukça düşük seviyede gerçekleştiği belirlenmiştir. 


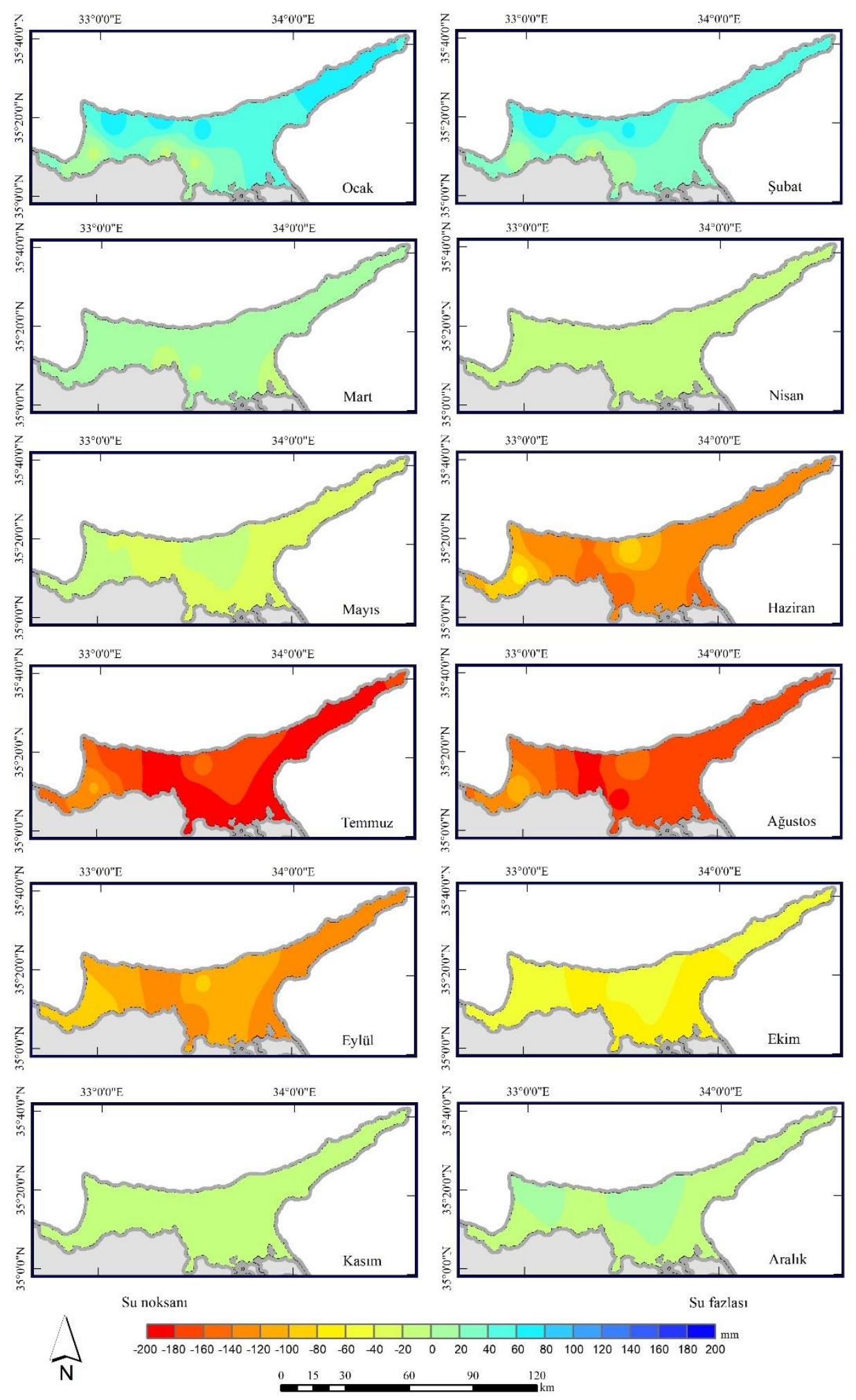

Şekil 3. Kuzey Kıbrıs’ta su noksanı ve fazlasının alansal dağılımı (1986-2016)

KKTC genelinde yılın çok büyük bir kısmında etkisini gösteren su noksanlığı mayıs ayından itibaren etkisini arttırmakta ve temmuz ayında en üst düzeye ulaşmaktadır (Şekil 3). Temmuz-ekim döneminde azalan bir eğilim ile etkisini gösteren su noksanlığı kasım ayından itibaren Kuzey Kıbrıs 
genelinde etkisini kaybetmeye başlamaktadır. Bu durum, ekim ayından itibaren başlayan yağışlar ve yaz mevsimine göre düşen sicaklık değerleri ile azalan buharlaşmanın tesirinde suyun görece olarak depolanmaya başlaması ile açıklanabilir. Su noksanlığının coğrafi dağılışı incelendiğinde Mesarya'nın orta ve doğusunda su noksanının özellikle temmuz ayında en üst düzeyde gerçekleştiği anlaşılmaktadır (Şekil 3). Su noksanlığı tespit edilen aylar boyunca su noksanının en düşük düzeyde gerçekleştiği bölge ise Güzelyurt (Batı Mesarya) Ovası ve yakın çevresi ile Alevkaya ve yakın çevresidir (Şekil 3). Kuzey Kıbrıs, Subtropikal kuşakta gelişen Akdeniz Makroklimasının özelliklerini yansıtmaktadır (Gönençgil ve Çavuş, 2006). Kuzey Kıbrıs genelinde topografya ve bakı iklim özelliklerinin farklılaşmasında oldukça önemli bir etkiye sahiptir (Öztürk, 2013). Bu kapsamda, Beşparmak Dağları'nın ada kuzeyindeki konumu ve yükseltisi dikkate alındığında, dulda yamaç subsidansına bağlı adyabatik 1sınmanın gerçekleşmesine neden olduğu anlaşı1ır. KKTC'nin en önemli akifer sistemine ev sahipliği yapan Batı Mesarya, batı-güney doğrultusunda Karlıdağ masifi ve kuzeybatıda Beşparmak Dağları tarafından çevrelenmektedir. Bu kapsamda, Güzelyurt Ovası'nın körfezden gelen nemli hava sisteminin KKTC içine geçişini kolaylaştıran bir kuşakta yer aldığı anlaşılır. Topografya ve bakının KKTC genelinde iklim özelliklerinin farklılaşmasındaki etkisi veri setini oluşturan istasyonların konumları dikkate alındığında istasyonlarda kaydedilen yağış miktarı ile doğrulanmaktadır. Özellikle Alevkaya ve yakın çevresinde kaydedilen düşük miktardaki su noksanı ile orta ve doğu Mesarya genelinde kaydedilen yüksek miktardaki su noksanı Beşparmak Dağları'nın iklim üzerindeki belirleyici etkisi ile açıklanabilir. Benzer durum Güzelyurt Ovası için de geçerlidir. Güzelyurt Ovası ve yakın çevresinin su noksanlığı tespit edilen aylar boyunca en düşük miktarda su noksanı gerçekleşen bölgeler arasında yer alması, ovanın konumu ve çevresindeki dağ kütlelerinin iklim üzerindeki belirleyici etkisi ile açıklanabilir.

Su noksanı ve su fazlası arasındaki en büyük farkın Lefkoşa, Ercan ve Gazimağusa istasyonlarında gerçekleştiği tespit edilmiştir. Söz konusu istasyonların coğrafi dağılımı dikkate alındığında, su noksanı ve su fazlası arasındaki farkın orta ve doğu Mesarya ovaları boyunca en yüksek seviyeye ulaştığı anlaşılmaktadır (Şekil 3). Bir başka ifade ile orta ve doğu Mesarya ovaları gerek su fazlalığı gerçekleşen aylarda Kuzey Kıbrıs geneline göre düşük miktarda su fazlası gerekse su noksanlığı gerçekleşen aylarda Kuzey Kıbrıs geneline göre yüksek miktarda su noksanı ile ön plana çıkmaktadır. Söz konusu bulgu; faklı araştırmacılar (Giannakopoulos vd., 2010; Zittis vd., 2020) tarafindan ada genelinde gerçekleştirilen projeksiyon çıtıları ile öngörülen durumun benzerinin 1986-2016 döneminde gerçekleştiğini göstermesi açısından önem taşımaktadır.

Kuzey Kıbrıs genelinde her bir su yılı için istasyonlara ait su bilançolarının ayrı ayrı hazırlanması ile üretilen veri setinden, su noksanlığ 1 ve su fazlalığ tespit edilen aylarda istatistiksel açıdan anlamlı bir artış veya azalış olup olmadığının belirlenmesi için gerçekleştirilen eğilim analizlerine ait sonuçlar Çizelge 2'de verilmiştir. Su fazlalığının gerçekleştiği aylarda negatif $u(t)$ değeri su fazlasındaki azalmayı, pozitif $u(t)$ değeri su fazlasındaki artışı ifade etmektedir. Benzer şekilde su noksanlığının gerçekleştiği aylarda ise negatif $u(t)$ değeri su noksanındaki azalmayı pozitif $u(t)$ değeri su noksanındaki artışı ifade etmektedir. 
Çizelge 2. Su noksanlığı ve fazlalığı sergileyen aylara ait eğilimler (1986-2016)

\begin{tabular}{|c|c|c|c|c|c|c|c|c|c|c|c|c|c|}
\hline & & Ekim & Kasım & Aralık & Ocak & Şubat & Mart & Nisan & Mayıs & Haziran & Temmuz & Ağustos & Eylül \\
\hline \multirow{4}{*}{$\begin{array}{l}\frac{\pi}{d} \\
\frac{\vec{J}}{d} \\
\frac{d}{<}\end{array}$} & $\mathrm{u}(\mathrm{t})$ & $-0,02$ & & $-0,49$ & 0,7 & $-0,87$ & $-3,28$ & & & $-0,08$ & 1,21 & 2,29 & 1,1 \\
\hline & Eğilim & yok & & yok & yok & yok & var & & & yok & yok & var & yok \\
\hline & Yön & --- & & --- & --- & --- & $\downarrow$ & & & --- & --- & $\uparrow$ & --- \\
\hline & Tarih & --- & & --- & --- & --- & 1991 & & & --- & --- & 1998 & --- \\
\hline \multirow{4}{*}{ 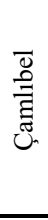 } & $\mathrm{u}(\mathrm{t})$ & 0,32 & & $-1,72$ & 1,24 & 0,59 & $-1,24$ & & 0,22 & 0,15 & 1,1 & 2,43 & 1,04 \\
\hline & Eğilim & yok & & yok & yok & yok & yok & & yok & yok & yok & var & yok \\
\hline & Yön & --- & & --- & --- & --- & --- & & --- & --- & --- & $\uparrow$ & --- \\
\hline & Tarih & --- & & --- & --- & --- & --- & & --- & --- & --- & 2005 & --- \\
\hline \multirow{4}{*}{ 胥 } & $\mathrm{u}(\mathrm{t})$ & 0,42 & & & & $-1,99$ & $-3,48$ & & $-0,32$ & 0,8 & 1,34 & 3,01 & 0,73 \\
\hline & Eğilim & yok & & & & var & var & & yok & yok & yok & var & yok \\
\hline & Yön & --- & & & & $\downarrow$ & $\downarrow$ & & --- & --- & --- & $\uparrow$ & --- \\
\hline & Tarih & --- & & & & 2010 & 1988 & & --- & --- & --- & 2005 & --- \\
\hline \multirow{4}{*}{ 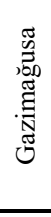 } & $\mathrm{u}(\mathrm{t})$ & $-0,05$ & 2,02 & & 0,29 & $-1,55$ & $-4,37$ & & 1,51 & 0,87 & 0,76 & 3,48 & 1,07 \\
\hline & Eğilim & yok & var & & yok & yok & var & & yok & yok & yok & var & yok \\
\hline & Yön & --- & $\uparrow$ & & --- & --- & $\downarrow$ & & --- & --- & --- & $\uparrow$ & --- \\
\hline & Tarih & --- & 1995 & & --- & --- & 1987 & & --- & --- & --- & 2001 & --- \\
\hline \multirow{4}{*}{ 志 } & $\mathrm{u}(\mathrm{t})$ & 0,32 & & & 0,97 & $-0,39$ & $-6,03$ & & 0,97 & 1,61 & 2,46 & 4,1 & 3,59 \\
\hline & Eğilim & yok & & & yok & yok & var & & yok & yok & var & var & var \\
\hline & Yön & --- & & & --- & --- & $\downarrow$ & & --- & --- & $\uparrow$ & $\uparrow$ & $\uparrow$ \\
\hline & Tarih & --- & & & --- & --- & 1988 & & --- & --- & 1995 & 1992 & 1990 \\
\hline \multirow{4}{*}{ 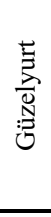 } & $\mathrm{u}(\mathrm{t})$ & 3,48 & & & & $-2,87$ & $-4,81$ & & & 3,96 & 4,54 & 4,95 & 3,96 \\
\hline & Eğilim & var & & & & var & var & & & var & var & var & var \\
\hline & Yön & $\uparrow$ & & & & $\downarrow$ & $\downarrow$ & & & $\uparrow$ & $\uparrow$ & $\uparrow$ & $\uparrow$ \\
\hline & Tarih & 2012 & & & & 1988 & 1988 & & & 2007 & 2007 & 2007 & 2007 \\
\hline \multirow{4}{*}{ 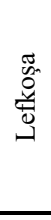 } & $\mathrm{u}(\mathrm{t})$ & $-0,12$ & 3,25 & & & & & & $-0,56$ & 1,07 & 1,24 & 3,38 & $-0,63$ \\
\hline & Eğilim & yok & var & & & & & & yok & yok & yok & var & yok \\
\hline & Yön & --- & $\uparrow$ & & & & & & --- & --- & --- & $\uparrow$ & --- \\
\hline & Tarih & --- & 1997 & & & & & & --- & --- & --- & 2001 & --- \\
\hline \multirow{4}{*}{ 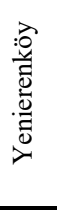 } & $\mathrm{u}(\mathrm{t})$ & 1,89 & & & 0,42 & $-1,34$ & $-3,79$ & & 0,39 & 1,82 & 1,24 & 1,65 & 0,59 \\
\hline & Ĕ̆ilim & yok & & & yok & yok & var & & yok & yok & yok & yok & yok \\
\hline & Yön & --- & & & --- & --- & $\downarrow$ & & --- & --- & --- & --- & --- \\
\hline & Tarih & --- & & & --- & --- & 1987 & & --- & --- & --- & --- & --- \\
\hline
\end{tabular}

Kuzey Kıbrıs genelinde su fazlalı̆̆ gerçekleşen aylara ait eğilim analizleri sonucunda, ayların tümü için ortak bir bulguya ulaşılamamıştır. Ocak ayında istasyonlarda \%99 veya \%95 güven aralıklarında anlamlı eğilim olmadığı tespit edilmiştir. Buna karşın hesaplanan $u(t)$ değerlerinin tümü 
pozitif olup bu durum su fazlasında anlamlı olmayan $(\alpha \neq 0,01$ veya $\alpha \neq 0,05)$ bir artışın yaşandığını ifade etmektedir. Şubat ayında Ercan ve Güzelyurt istasyonlarında su fazlalığında azalma eğilimi $(\alpha=$ $0,05)$ tespit edilmiştir. Ercan ve Güzelyurt istasyonları için çizilen $u(t)$ ve $u^{\prime}(t)$ grafiğinden eğilimin başlangıç tarihi sırası ile 2010 ve 1988 olarak belirlenmiştir. Şubat ayında, Çamlıbel istasyonu dışında anlamlı eğilim tespit edilemeyen istasyonların tamamında $u(t)$ değerlerinin negatif olduğu belirlenmiştir. Bu durum, su fazlasında anlamlı olmayan $(\alpha \neq 0,01$ veya $\alpha \neq 0,05)$ bir azalışın yaşandığını göstermektedir. Mart ayında Çamlıbel istasyonu haricinde tüm su fazlası olan istasyonlarda istatistiksel açıdan yüksek anlamlılık düzeyine sahip $(\alpha=0,01)$ ve negatif değerli eğilim tespit edilmiştir. Alevkaya, Ercan, Gazimağusa, Girne, Güzelyurt ve Yenierenköy istasyonları için çizilen $u(t)$ ve $u^{\prime}(t)$ grafiklerinden su fazlalığındaki azalma eğilimi başlangıçlarının sırası ile 1991, 1988, 1987, 1988, 1988 ve 1987 yıllarına tarihlendiği belirlenmiştir. Aralık ayında su fazlalığı sergileyen istasyonlar için anlamlı $(\alpha=0,01$ veya $\alpha=0,05)$ bir eğilim olmadığı belirlenmiştir.

Kuzey Kıbrıs genelinde su noksanlığı gerçekleșen aylara ait eğilim analizleri sonucunda, su fazlalığı gerçekleşen aylara benzer şekilde, ayların tümü için ortak bir bulguya ulaşılamamıştır. Mayıs ayında su noksanlığı olan istasyonların tamamında anlamlı ( $\alpha=0,01$ veya $\alpha=0,05)$ herhangi bir eğilim olmadığı belirlenmiştir. Haziran ayında sadece Güzelyurt istasyonunda istatistiksel açıdan yüksek anlamlılık düzeyine sahip $(\alpha=0,01)$ su noksanı artış eğilimi tespit edilmiştir. Haziran ayında Güzelyurt istasyonuna ait $u(t)$ ve $u^{\prime}(t)$ grafiğinden su noksanlığındaki azalma eğilimi başlangıcının 2007 yılına tarihlendiği belirlenmiştir. Temmuz ayı genelinde tüm istasyonlarda eğilim analizi sonuçları pozitif değerli olup, bu durum su noksanı artışını göstermesi açısından önemlidir. Temmuz ayında su noksanlığı sergileyen istasyonlar arasında Girne ve Güzelyurt istasyonları öne çıkmaktadır. Temmuz ayı su noksanlığında, Girne istasyonu için 0,05 anlamlılık düzeyinde ve Güzelyurt istasyonu için 0,01 anlamlılık düzeyinde artış eğilimi olduğu ortaya çıkartılmıştır. Temmuz ayına benzer şekilde ağustos ayı genelinde tüm istasyonlarda eğilim analizi sonuçları pozitiftir. Ağustos ayı su noksanlı̆̆ında Yenierenköy istasyonu dışındaki tüm istasyonlarda istatistiksel açıdan anlamlı $(\alpha=0,01$ veya $\alpha=0,05)$ artış eğilimi tespit edilmiştir. Ağustos ayında \%95 güven aralığında anlamlı eğilim tespit edilen Alevkaya ve Çamlıbel istasyonları için çizilen $u(t)$ ve $u^{\prime}(t)$ grafiklerinden su noksanlığındaki artış eğilimi başlangıçlarının sırası ile 1998 ve 2005 yıllarına tarihlendiği belirlenmiştir. Aynı ayda \%99 güven aralığında anlamlı eğilim tespit edilen Ercan, Gazimağusa, Girne, Güzelyurt ve Lefkoşa istasyonları için çizilen $u(t)$ ve $u^{\prime}(t)$ grafiklerinden su noksanlığındaki artış eğilimi başlangıçlarının sırası ile 2005, 2001, 1992, 2007 ve 2001 yıllarına tarihlendiği belirlenmiştir. Eylül ayında Lefkoşa istasyonu dışında tüm istasyonlar için eğilim analizi sonuçlarının pozitif değerli olduğu bulgusuna ulaşılmıştır. Aynı ayda, Girne ve Güzelyurt istasyonlarında ise istatistiksel açıdan yüksek anlamlılık düzeyinde $(\alpha=0,01)$ eğilimlerin gerçekleştiği tespit edilmiştir. Eylül ayında Girne ve Güzelyurt istasyonları için çizilen $u(t)$ ve $u^{\prime}(t)$ grafiklerinden su noksanlığındaki artış eğiliminin başlangıç tarihleri sırası ile 1990 ve 2007 yılları olarak belirlenmiştir. Ekim ayında, Güzelyurt istasyonunda istatistiksel açıdan oldukça yüksek anlamlılık düzeyine sahip $(\alpha=0,01)$ ve pozitif değerli eğilim bulgusu tespit edilmiştir. Ekim ayında Güzelyurt istasyonu için çizilen $u(t)$ ve $u^{\prime}(t)$ grafiğinden su noksanlığındaki artış eğiliminin başlangıç tarihi 2012 yılı olarak belirlenmiştir. 
Su fazlalığı olan aylar için eğilim analizlerinin alansal dağılımı incelendiğinde Orta Mesarya Ovası ve yakın çevresinde su fazlalığının kuvvetli şekilde azaldığı bulgusuna ulaşılmıştır (Şekil 4). Özellikle su fazlalığının en düşük seviyede gerçekleştiği mart ayında Beşparmak Dağları'nın denize bakan yamaçları ile birlikte Güzelyurt ve Gazimağusa körfezleri arasında yayılım gösteren Güzelyurt, orta ve doğu Mesarya ovaları genelinde su fazlalığındaki azalışın belirgin şekilde kuvvetlendiği belirlenmiştir. Mart ayında su fazlalığının diğer aylara göre oldukça düşük olduğu bulgusu, yüksek anlamlılık düzeyine sahip azalma eğilimi ve tespit edilen eğilimin devam etmesi varsayımı dikkate alındığında; oldukça kısa bir süre sonunda mart ayının KKTC genelinde su noksanlığı gerçekleşen aylar arasında yer alacağ 1 ve buna bağlı olarak yıl genelinde su noksanlığı süresinde artış gerçekleşeceği öngörülmektedir. Su noksanlığı tespit edilen aylara ait eğilim analizlerinin alansal dağılımı incelendiğinde Kuzey Kıbrıs genelinde su noksanlığı yaşanan aylarda genel olarak noksanlık eğiliminde artış gerçekleştiği bulgusuna ulaşılmıştır (Şekil 5). Söz konusu bulgu ve farklı çalışmalara ait gelecek projeksiyonları (Giannakopoulos vd., 2010; Zittis vd., 2020) bir arada değerlendirildiğinde; Kuzey Kıbrıs genelinde su noksanlığı gerçekleşen aylar için su noksanlığının daha da kuvvetleneceği öngörülmektedir.
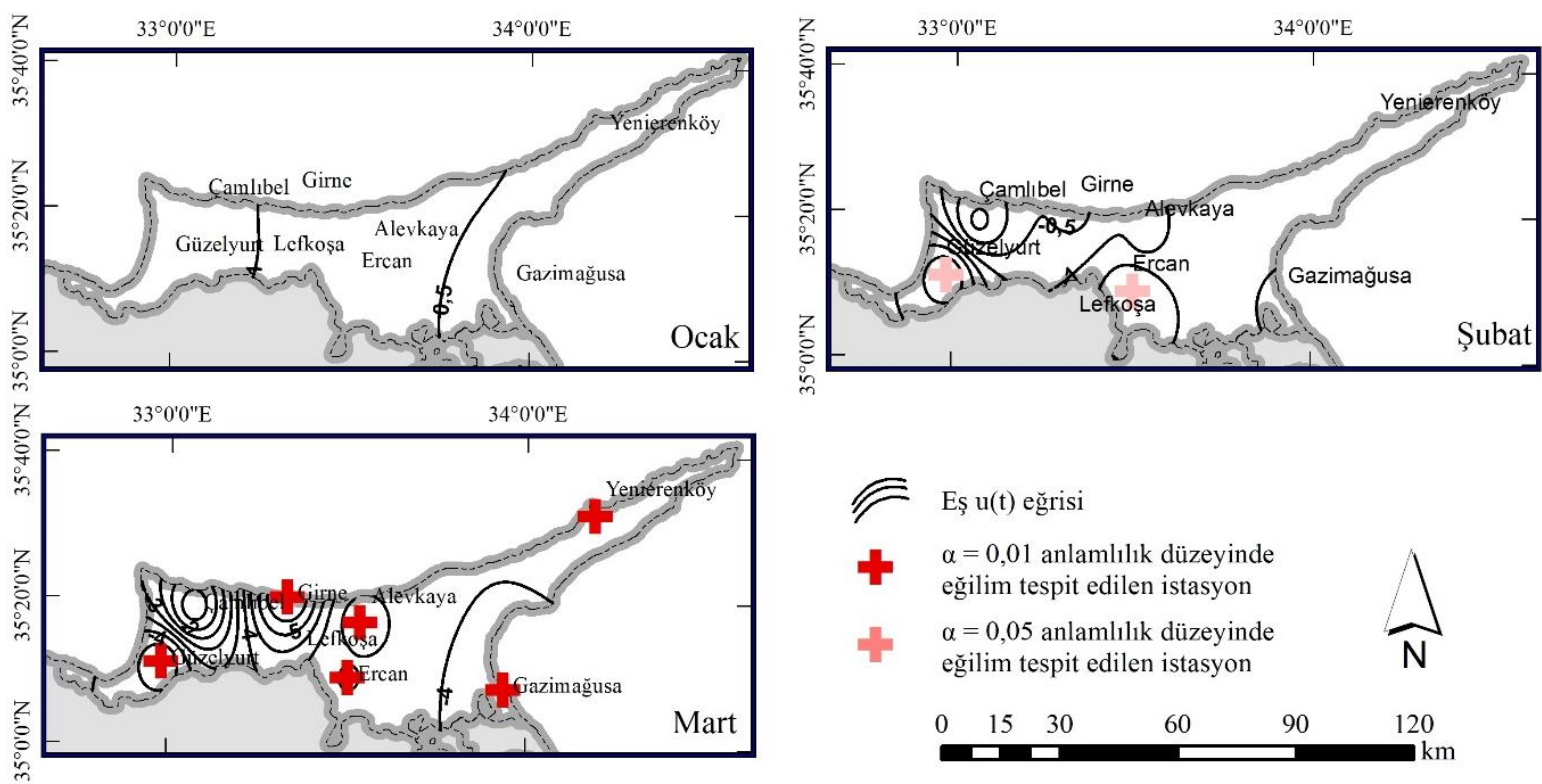

Şekil 4. Su fazlası olan aylar için Mann-Kendall sıra korelasyon istatistik değerlerinin alansal dağılımı (1986-2016) 

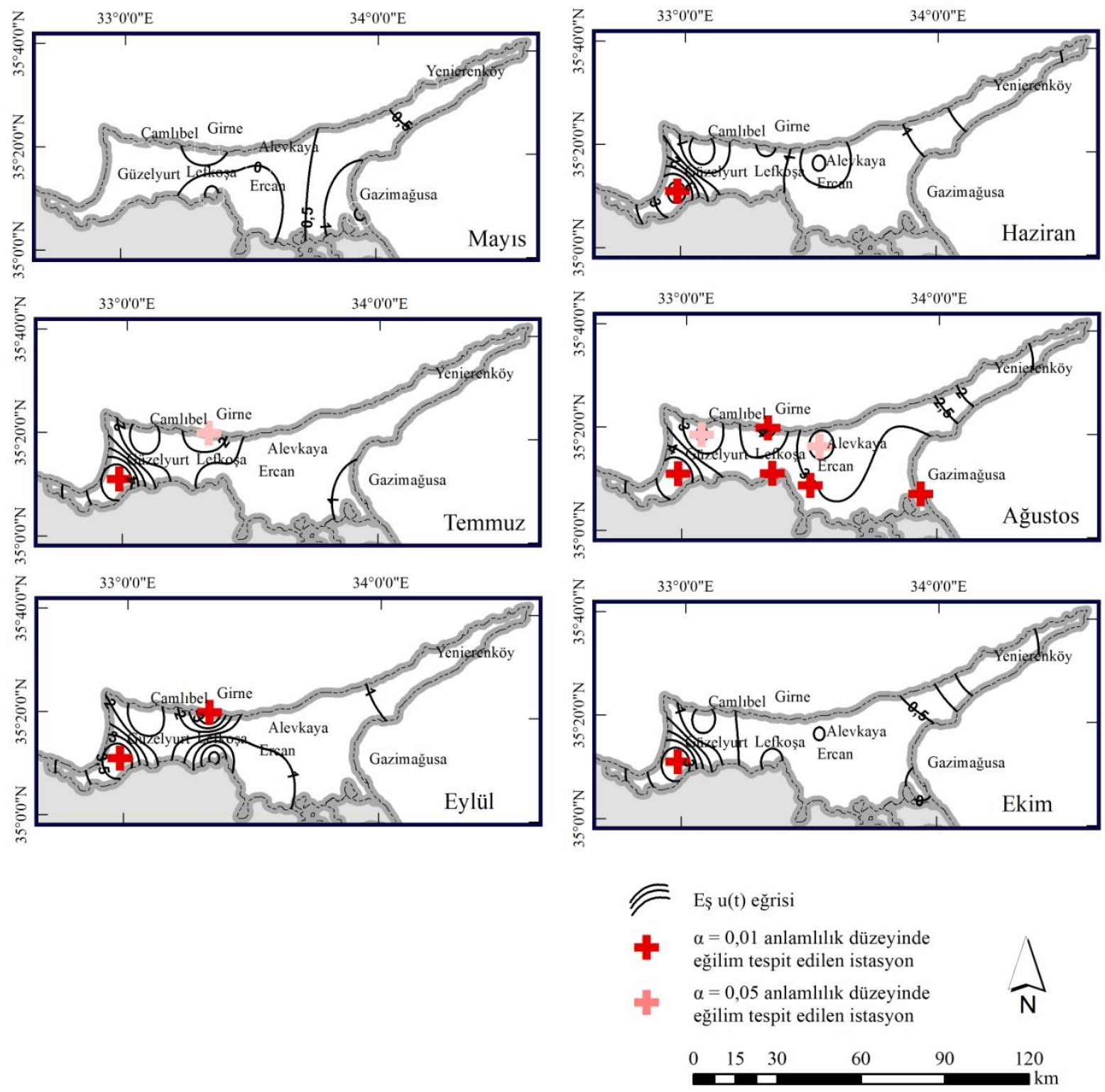

Şekil 5. Su noksanı olan aylar için Mann-Kendall sıra korelasyon istatistik değerlerinin alansal dağılımı (1986-2016)

1986-2016 yılları arasındaki otuz bir yıllık kesintisiz dönem boyunca su noksanlığı ve fazlalığı olan aylar için eğilim analizlerinin alansal dağılımı bir arada değerlendirildiğinde Güzelyurt Ovası ve yakın çevresi gerek yüksek $u(t)$ değerleri gerekse sergilediği yüksek anlamlılık düzeyindeki eğilimler ile ön plana çıkmaktadır (Şekil 4 ve Şekil 5). Güzelyurt Ovası ve yakın çevresi şubat ve mart aylarında su fazlalığında anlamlı azalma eğilimi sergilemiştir. Benzer şekilde ova ve yakın çevresi haziran, temmuz, ağustos, eylül ve ekim aylarında su noksanlığında yüksek anlamlılık düzeyinde artış eğilimi sergilemiştir. Gerek Kuzey Kıbrıs'ın en büyük yeraltı su kaynağı beslenim sahasına dâhil olması gerekse yeraltı suyunun varlığından dolayı Kuzey Kıbrıs tarımının büyük bir kısmına ev sahipliği yapması nedenleri ile Güzelyurt Ovası KKTC için stratejik öneme sahip bölgeler arasında yer almaktadır. KKTC'nin en önemli tatlı su kaynağı olan Güzelyurt akiferi besleniminde yağışlı dönemi temsil eden aralık, ocak ve şubat aylarında kaydedilen yağışlar büyük önem taşımaktadır (Ergil, 2020). Güzelyurt 
Ovası ve yakın çevresinde şubat ayı için tespit edilen su fazlalığındaki anlamlı azalma eğilimi ile birlikte görece yağışın yüksek olduğu mart ayında tespit edilen yüksek anlamlılık düzeyindeki azalma eğilimi akifer besleniminde gelir kaybı olduğunu göstermesi açısından önemlidir. 1988 yılına tarihlenen eğilim başlangıcı, özellikle bu tarihten sonra akiferin gelir kaybındaki azalmanın (aşırı su çekimi olmaksızın) hissedilebilir bir düzeye ulaştığını göstermektedir. Bir başka ifade ile atmosferdeki pozitif yönlü ışınımsal zorlama Kuzey Kıbrıs'ın en önemli su kaynağı olan Güzelyurt Akiferi üzerinde 1988 yılından itibaren su fazlalılığında anlamlı azalma eğilimi ile kendini göstermiştir. Benzer durum KKTC genelindeki tüm akifer sistemleri için geçerlidir. Akiferlerin Kuzey Kıbrıs’ta yer alan beslenme sahalarında tespit edilen anlamlı eğilimler KKTC'nin en önemli yenilenebilir su kaynaklarının gelirinde kayıplar gerçekleştiğini göstermesi açısından büyük önem taşımaktadır.

1986-2016 yılları arasındaki otuz bir yıllık kesintisiz dönem boyunca Kuzey Kıbrıs genelinde yıllara göre su noksanı ve su fazlası olan ay sayıları üzerinden gerçekleştirilen bir diğer eğilim analizi sonucuna göre su noksanı ve su fazlası ay sayıları için $u(t)$ değerleri sırası ile $-1,20$ ve $-2,50$ olarak hesaplanmıştır. Bu durum, 1986-2016 döneminde yıllara göre su fazlası olan ay sayılarında anlamlı azalma eğilimi $(\alpha=0,05)$ gerçekleştiğini göstermektedir. Yı1lara göre su fazlası olan ay sayıları için çizilen $u(t)$ ve $u^{\prime}(t)$ grafiğinden azalma eğilimi başlangıcının 1991 yılına tarihlendiği belirlenmiştir.

\section{Sonuç}

KKTC, yenilenebilir su kaynakları açısından kendi kendine yetebilme seviyesinden uzak olup aynı zamanda mutlak su kıtlığı ekseninde su problemi ile mücadele etmektedir. Artan iklim değişikliği baskısı ile birlikte, atmosferdeki pozitif yönlü ışınımsal zorlamanın KKTC su kaynakları üzerinde kendini ne şekilde gösterdiği ve su bütçesi üzerindeki etkilerinin hangi düzeyde olduğu önemli sorunlar arasında yer almaktadır. Bu çalışmada, Kuzey Kıbrıs'ta 1986-2016 yılları arasındaki otuz bir yıllık dönem boyunca gerçekleşen su noksanlığının ortaya çıkartılması ve su noksanlığına ait eğilimlerin araştırılması amaçlanmıştır.

Çalışma bulguları Kuzey Kıbrıs genelinde yılın büyük bir kısmında su noksanlığı gerçekleştiğini göstermektedir. Su noksanı miktar ve süresi Kuzey Kıbrıs genelinde homojen değildir. Özellikle kuzey ve iç kesimler arasında su noksanı miktar ve süresi farklıklar sergilemektedir. KKTC'nin iç kesimlerinde su yılının \%53'ünde su noksanlığı gerçekleştiği (en yüksek \%58 en düşük \%50) ve su noksanı miktarının $752 \mathrm{~mm} / \mathrm{y} 1 \mathrm{l}$ (en yüksek $760 \mathrm{~mm} / \mathrm{y} 1 \mathrm{l}$ en düşük $744 \mathrm{~mm} / \mathrm{y} 1$ ) düzeyinde olduğu belirlenmiştir. Güzelyurt ve Gazimağusa körfezleri arasındaki kuzeybat1-güneydoğu doğrultusu boyunca su noksanlı̆̆ süresi artmaktadır. Su noksanı miktarı Orta Mesarya Ovası'nda en yüksek seviyeye ulaşmaktadır. KKTC'nin kuzey kesimlerinde ise su yılının \%47'sinde su noksanlığı gerçekleştiği (en yüksek \%50 en düşük \%42) ve su noksanı miktarının 614 mm/yıl (en yüksek 760 mm/yıl en düşük 430 mm/yıl) düzeyinde olduğu belirlenmiştir. Güzelyurt Körfezi ve Karpaz Yarımadası arasındaki batı-doğu doğrultusu boyunca su noksanlığ 1 süresi artmaktadır. KKTC'nin kuzeyinde, su noksanı miktarı Girne ve yakın çevresinde en yüksek seviyeye ulaşmaktadır.

Eğilim analizleri Kuzey Kıbrıs genelinde gerek su fazlalı̆̆ında gerekse su noksanlı̆̆ında istatistiksel açıdan anlamlı yönelimler gerçekleştiğini ortaya çıkartmıştır. Su fazlalığı kaydedilen aylarda tespit edilen anlamlı eğilimler su fazlasının azaldığını gösterirken, su noksanlığı kaydedilen aylarda 
tespit edilen anlamlı eğilimler su noksanının arttığını göstermiştir. Otuz bir yıllık kesintisiz dönem boyunca yıllık ölçekte su fazlası olan ay sayısında anlamlı azalma eğilimi tespit edilmiştir. Eğilimlerin devam etmesi ile su noksanı miktar ve süresinde Kuzey Kıbrıs genelinde artış yaşanacağı öngörülmektedir.

\section{Teşekkür ve Bilgilendirme}

Bu çalışmada, hesaplama ve analizler için gerekli olan veri seti Kuzey Kıbrıs Türk Cumhuriyeti Meteoroloji Dairesi'nden temin edilmiştir. Yazar, çalışma için gerekli olan veri setinin temininde gösterdiği destek için Kuzey Kıbrıs Türk Cumhuriyeti Meteoroloji Dairesi ile değerli çalışanlarına ve ayrıca çalışmanın değerlendirilme sürecinde yapıcı öneriler sunarak çalışmanın olgunlaşmasına katkı sağlayan isimlerini bilmediği hakemlere teşekkür eder. 


\begin{tabular}{ccc} 
Coğrafi Bilimler Dergisi & Cografi \\
Bilimler & Dergisi \\
\hline
\end{tabular}

\title{
Water Deficit and Trend Analysis in the Turkish Republic of Northern Cyprus
}

\author{
M. Murat Kale*a
}

\section{EXTENDED ABSTRACT}

\section{Introduction}

The Earth has a different position among all known planets owing to its water resources as well as its water cycle system (hydrological cycle), which allows water resources to move between the ground and atmospheric systems. The hydrological cycle, which has a dynamic structure, is extremely sensitive to changes occurring in the ground and subsystems of the atmosphere (Chahine, 1992; Huntington, 2006). As long as there are no changes in subsystems, no major changes are expected in the presence, amount, and distribution of freshwater in a specific region over relatively long periods, while an intense pressure arises on freshwater resources in the opposite case (Chahine, 1992; Hutjes et al., 1998).

According to the Falkenmark index, the Turkish Republic of Northern Cyprus (TRNC), which is discussed in this study, is among the countries suffering from absolute water scarcity with a renewable water amount of $328 \mathrm{~m}^{3} /$ year per capita (Y1lmaz, 2020). In the TRNC, with a surface area of 3,354 $\mathrm{km}^{2}$, there are no rivers with permanent flow characteristics (Kutoğlu, 2010). The TRNC is highly dependent on groundwater (Koday, 1995; Şenol, 2020). The TRNC is located in a geography that has scarcer freshwater resources compared to its southern neighbor and is relatively dependent on the south, considering the recharge characteristics of the renewable water resources. Morphological characteristics, along with high evaporation and low precipitation in the TRNC, do not allow for storing a high amount of water in dams (Maden, 2013). The TRNC, which is highly dependent on groundwater, has a salinization problem in coastal aquifers (Ergil, 2000).

In this study, it was aimed to reveal the water deficit in the TRNC and investigate water deficit trends. In this context, it was intended to determine changes in the amount, duration, and trends of water deficit-surplus.

\section{Methodology}

In this study, which aimed to reveal the water deficit in the TRNC and investigate water deficit trends, long-term water balances (budgets) were calculated, and months with water deficit and water surplus were determined. The presence of the trend and its start date were investigated by performing trend analyses for the specified months.

\footnotetext{
* Corresponding Author: mmuratkale@mail.com

${ }^{a}$ Çankırı Karatekin University, Faculty of Letters, Geography Department, Çankırı/Turkey, https://orcid.org/0000-0001-69757069 .
} 
The data set covering the records of eight different stations belonging to the thirty-one-year uninterrupted period between 1986 and 2016 was obtained from the TRNC Meteorology Department. Basic information about the stations is given in Table 1.

Table 1. Basic information about the observation stations

\begin{tabular}{|c|c|c|c|c|c|c|}
\hline \multirow{2}{*}{ Name of station } & \multirow{2}{*}{$\begin{array}{l}\text { Number of } \\
\text { station }\end{array}$} & \multicolumn{2}{|c|}{ Location } & \multirow{2}{*}{ Altitude (m) } & \multicolumn{2}{|c|}{ Time series } \\
\hline & & Latitude & Longitude & & Starting & Ending \\
\hline Alevkaya & 17560 & $35^{\circ} 17^{\prime} 05.47^{\prime \prime} \mathrm{K}$ & $33^{\circ} 32^{\prime} 04.26^{\prime \prime} \mathrm{D}$ & 631 & 1986 & 2016 \\
\hline Çamlibel & 17570 & $35^{\circ} 18^{\prime} 54.56^{\prime \prime} \mathrm{K}$ & $33^{\circ} 04^{\prime} 12.33^{\prime \prime} \mathrm{D}$ & 271 & 1986 & 2016 \\
\hline Ercan & 17521 & $35^{\circ} 09^{\prime} 10.40^{\prime \prime} \mathrm{K}$ & $33^{\circ} 30^{\prime} 42.49^{\prime \prime} \mathrm{D}$ & 112 & 1986 & 2016 \\
\hline Girne & 17510 & $35^{\circ} 20^{\prime} 27.21^{\prime \prime} \mathrm{K}$ & $33^{\circ} 19^{\prime} 52.19^{\prime \prime} \mathrm{D}$ & 7 & 1986 & 2016 \\
\hline Güzelyurt & 17500 & $35^{\circ} 11^{\prime} 27.21^{\prime \prime} \mathrm{K}$ & $32^{\circ} 58^{\prime} 53.82^{\prime \prime} \mathrm{D}$ & 49 & 1986 & 2016 \\
\hline Lefkoşa & 17515 & $35^{\circ} 12^{\prime} 46.45^{\prime \prime} \mathrm{K}$ & $33^{\circ} 21^{\prime} 07.98^{\prime \prime} \mathrm{D}$ & 133 & 1986 & 2016 \\
\hline Gazimağusa & 17540 & $35^{\circ} 08^{\prime} 07.20^{\prime \prime} \mathrm{K}$ & $33^{\circ} 56^{\prime} 34.38^{\prime \prime} \mathrm{D}$ & 4 & 1986 & 2016 \\
\hline Yenierenköy & 17550 & $35^{\circ} 31^{\prime} 30.32^{\prime \prime} \mathrm{K}$ & $34^{\circ} 10^{\prime} 28.14^{\prime \prime} \mathrm{D}$ & 121 & 1986 & 2016 \\
\hline
\end{tabular}

It was decided to use non-parametric methods in homogeneity testing since the data set was at the lower limit quantitatively and did not fit the normal distribution function. The Kruskal-Wallis ( $\mathrm{K}-$ W) test was performed for homogeneity testing (Sneyers, 1990).

In this study, Etp calculations were made using the Thornthwaite (1948) method, which is widely preferred in the literature due to the scarcity and practicality of the inputs needed during calculations.

The Mann-Kendall (M-K) rank correlation test statistics, one of the non-parametric methods, was used for trend analyses performed throughout the study. (Sneyers, 1990).

\section{Results and Discussion}

The graphical representation of the long-term (1986-2016) water balances (budgets) calculated on a station basis according to the Thornthwaite (1948) method is given in Figure 2.

Considering the long-term water balances of the stations for the thirty-one-year uninterrupted period between 1986 and 2016, across the TRNC, the months with water surplus were found to be January, February, and March, and the months with water deficit to be May, June, July, August, September, and October. In the same period, it was determined that the number of months during which water surplus was observed at the stations located in the north of the TRNC was higher than the other stations, and the amount and duration of water deficit were much higher at the stations located in the inner parts. It was revealed that water surplus at any station was not quantitatively greater than the water deficit at the same station, and the stations faced water deficit for an exceedingly long time throughout the year. Among the months with water surplus across Northern Cyprus, February was observed to stand out with the highest amount of water surplus. On the other hand, among the months with water deficit, July was found to come to the fore with the highest amount of water deficit. 

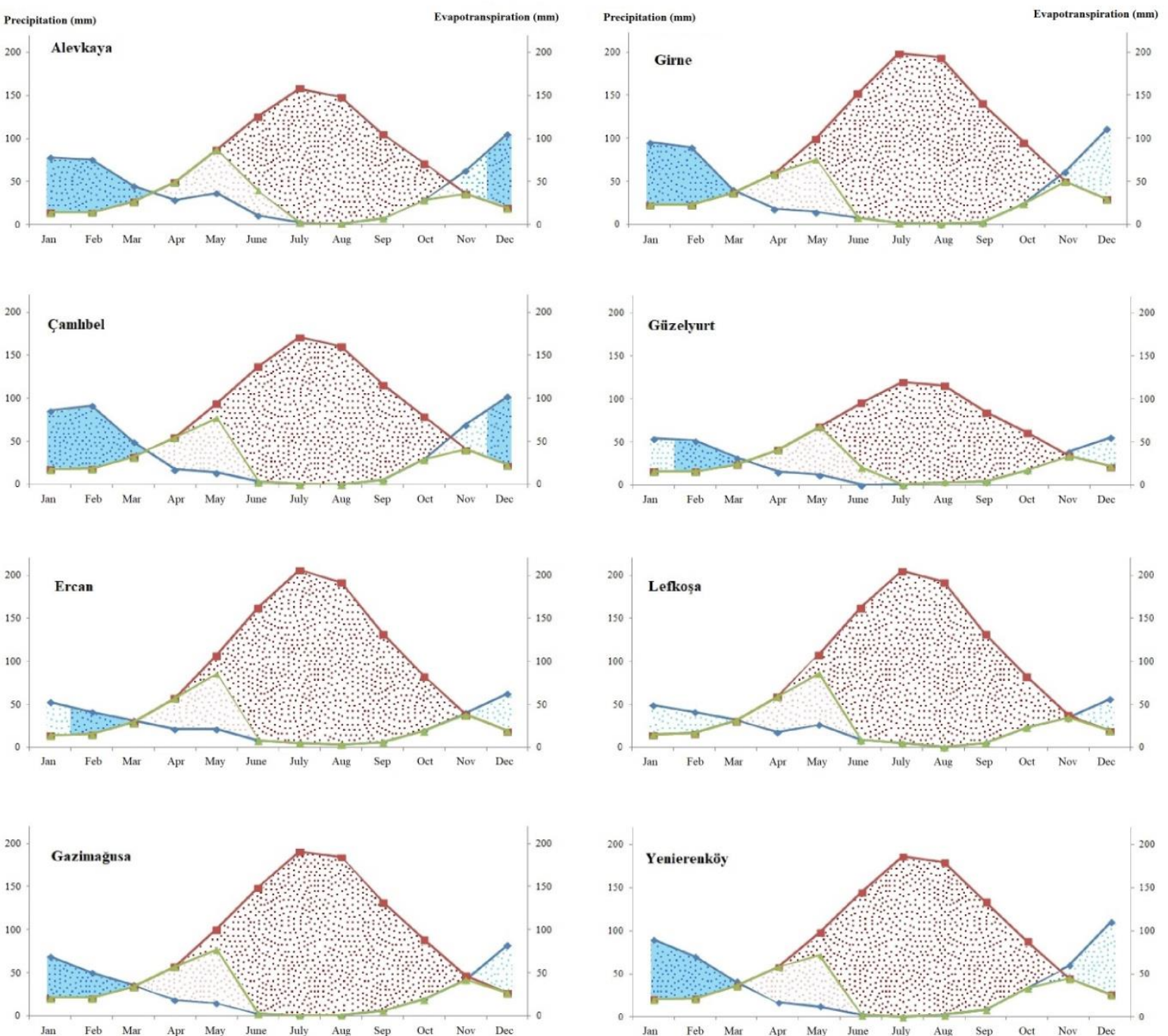

$\multimap$ Precipiation (p) $\rightarrow$ Potential evapotranspiration (Etp) $\quad$ Actual evapotranspiration (Eta)
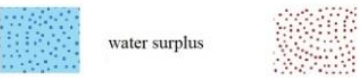

Figure 2. The graphical representation of water budget (1986-2016) according to the Thornthwaite (1948)

The monthly areal distribution of water deficit and surplus across the TRNC, generated by using the Inverse Distance Weighting Interpolation (IDW) method, is given in Figure 3. A significant difference was observed between the northern and inner regions of Northern Cyprus in the areal distribution of water surplus (Figure 3). Along the Beşparmak Mountains (1,024 m), located in the north of the TRNC and forming the country's highest elevation, water surplus reaches its highest level in the Çamlıbel-Yenierenköy axis. On the other hand, in January and February, there was no water surplus or water surplus was at an extremely low level in Mesaoria and especially in Güzelyurt and its immediate surroundings located in the west of Mesaoria (the Güzelyurt Plain) and in Nicosia and its immediate surroundings located in the middle of Mesaoria (the Middle Mesaoria Plain). 


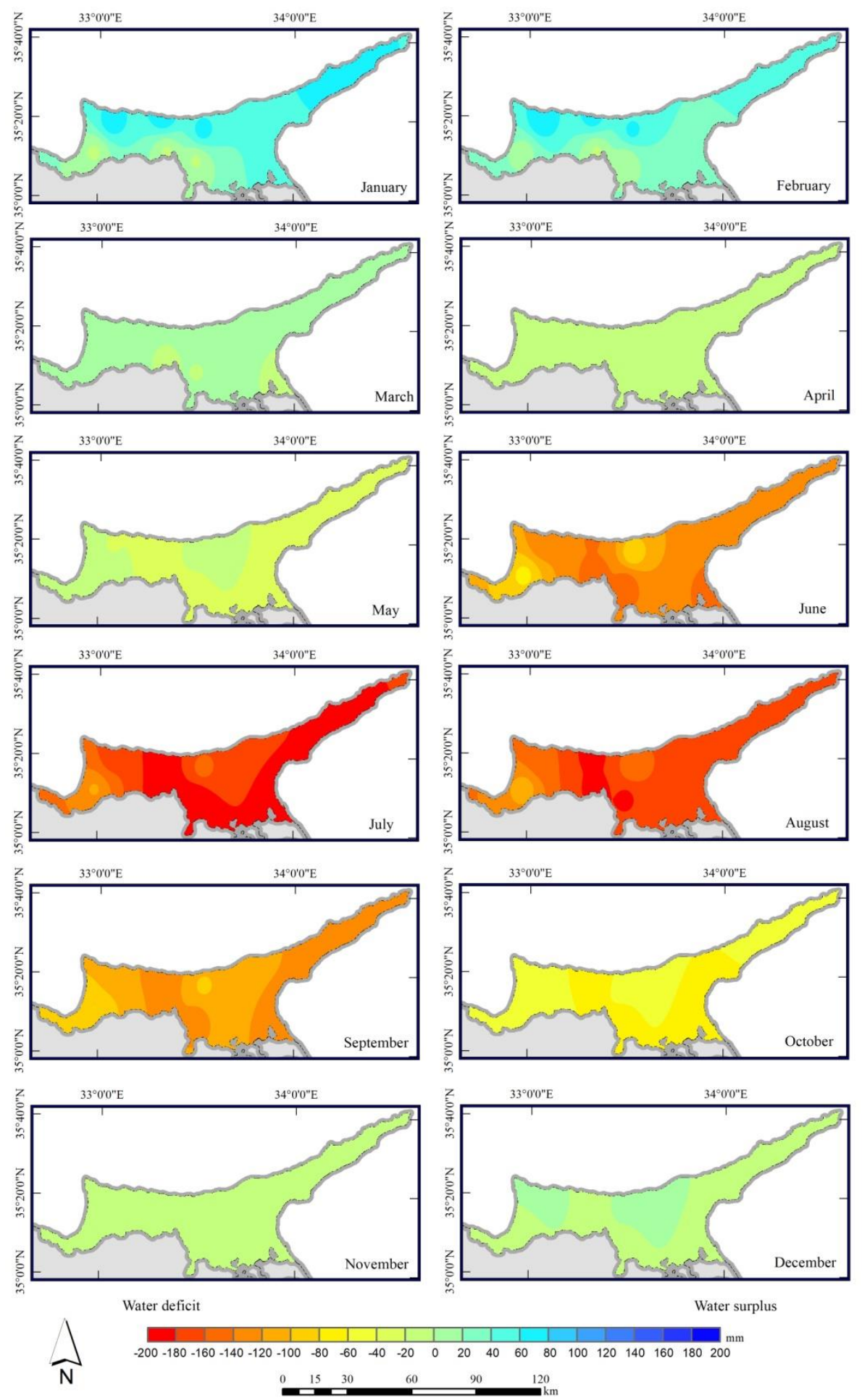

Figure 3. Spatial distribution of water deficit and surplus in Northern Cyprus (1986-2016)

When the geographical distribution of water deficit is examined, it is understood that water deficit occurs especially in July at the highest level in the middle and east of Mesaoria (Figure 3). During the months when water deficit is observed, the region where water deficit occurs at the lowest level is 
the Güzelyurt (Western Mesaoria) Plain and its immediate surroundings and Alevkaya and its immediate surroundings (Figure 3). Northern Cyprus reflects the characteristics of the Mediterranean macroclimate developing in the subtropical zone (Gönençgil and Çavuş, 2006). Topography and aspect have an extremely important effect on the differentiation of climatic characteristics throughout Northern Cyprus. (Öztürk, 2013). In this context, when the location and elevation of the Beşparmak Mountains in the north of the island are considered, it is realized that the afore-stated effect causes adiabatic warming resulting from the leeward subsidence. Western Mesaoria, which hosts the most important aquifer system of the TRNC, is surrounded by the Karlıdag massif in the west-south direction and the Beşparmak Mountains in the northwest. In this sense, it is understood that the Güzelyurt Plain is located in a belt that facilitates the passage of the humid air system coming from the bay into the TRNC. The effect of topography and slope exposure on the differentiation of climate characteristics throughout the TRNC is confirmed by the amount of precipitation recorded at the stations, when the locations of the stations that comprise the data set are taken into account. Especially the low amount of water deficit recorded in Alevkaya and its immediate surroundings and the high amount of water deficit recorded in the central and eastern Mesaoria can be explained by the determinative effect of the Beşparmak Mountains on the climate. The same is valid for the Güzelyurt Plain. The fact that the Güzelyurt Plain and its immediate surroundings are among the regions with the lowest amount of water deficit during the months with water deficit can be explained by the location of the plain and the determinative effect of the surrounding mountain masses on the climate.

The results of the trend analyses conducted throughout Northern Cyprus are presented in Table 2.

When the areal distribution of the trend analyses for the months with water surplus was examined, it was found that water surplus in the Middle Mesaoria Plain and its immediate surroundings decreased intensively (Figure 4). It was determined that the decrease in water surplus was significantly intensified in the Güzelyurt, Central and Eastern Mesaoria Plains, which spread between the Güzelyurt and Gazimagusa gulfs, along with the slopes of the Beşparmak Mountains facing the sea, particularly in March, when water surplus was at the lowest level. When the areal distribution of the trend analyses of the months with water deficit was examined, a general increase was found in the deficit trend in the months with water deficit throughout Northern Cyprus (Figure 5).

Significant trends detected in the recharge areas of aquifers in Northern Cyprus are crucial for indicating that there are losses in the income of the most important renewable water resources of the TRNC.

According to the results of another trend analysis conducted over the number of months with water deficit and water surplus throughout Northern Cyprus during the thirty-one-year uninterrupted period between 1986 and 2016, $\mathrm{u}(\mathrm{t})$ values were calculated as -1.20 and -2.50 for the numbers of months with water deficit and water surplus, respectively. This shows a significant decrease trend in the number of months with water surplus $(\alpha=0.05)$ by year between 1986 and 2016. It was found that the start of the decrease trend dated back to 1991 in the graphs $u(t)$ and $u^{\prime}(t)$ drawn for the number of months with water surplus by year. 
Table 2. Trends for the months exhibiting water deficit and surplus (1986-2016)

\begin{tabular}{|c|c|c|c|c|c|c|c|c|c|c|c|c|c|}
\hline & & Oct & Nov & Dec & Jan & $\mathrm{Feb}$ & Mar & Apr & May & June & July & Aug & Sep \\
\hline \multirow{4}{*}{$\begin{array}{l}\frac{\pi}{\vec{J}} \\
\frac{\vec{\pi}}{d} \\
\frac{d}{<}\end{array}$} & $\mathrm{u}(\mathrm{t})$ & -0.02 & & -0.49 & 0.7 & -0.87 & -3.28 & & & -0.08 & 1.21 & 2.29 & 1.1 \\
\hline & Trend & no & & no & no & no & yes & & & no & no & yes & no \\
\hline & Direction & --- & & --- & --- & --- & $\downarrow$ & & & --- & --- & $\uparrow$ & --- \\
\hline & Date & --- & & --- & --- & --- & 1991 & & & --- & --- & 1998 & --- \\
\hline \multirow{4}{*}{$\begin{array}{l}\bar{\Xi} \\
\text { है } \\
\text { U్ } \\
\text { U. }\end{array}$} & $\mathrm{u}(\mathrm{t})$ & 0.32 & & -1.72 & 1.24 & 0.59 & -1.24 & & 0.22 & 0.15 & 1.1 & 2.43 & 1.04 \\
\hline & Trend & no & & no & no & no & no & & no & no & no & yes & no \\
\hline & Direction & --- & & --- & --- & --- & --- & & --- & --- & --- & $\uparrow$ & --- \\
\hline & Date & --- & & --- & --- & --- & -- & & --- & --- & --- & 2005 & --- \\
\hline \multirow{4}{*}{ 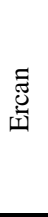 } & $\mathrm{u}(\mathrm{t})$ & 0.42 & & & & -1.99 & -3.48 & & -0.32 & 0.8 & 1.34 & 3.01 & 0.73 \\
\hline & Trend & no & & & & yes & yes & & no & no & no & yes & no \\
\hline & Direction & --- & & & & $\downarrow$ & $\downarrow$ & & --- & --- & --- & $\uparrow$ & --- \\
\hline & Date & --- & & & & 2010 & 1988 & & --- & --- & --- & 2005 & --- \\
\hline \multirow{4}{*}{ 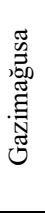 } & $\mathrm{u}(\mathrm{t})$ & -0.05 & 2.02 & & 0.29 & -1.55 & -4.37 & & 1.51 & 0.87 & 0.76 & 3.48 & 1.07 \\
\hline & Trend & no & yes & & no & no & yes & & no & no & no & yes & no \\
\hline & Direction & --- & $\uparrow$ & & --- & --- & $\downarrow$ & & --- & --- & --- & $\uparrow$ & --- \\
\hline & Date & --- & 1995 & & --- & --- & 1987 & & --- & --- & --- & 2001 & --- \\
\hline \multirow{4}{*}{ 节 } & $\mathrm{u}(\mathrm{t})$ & 0.32 & & & 0.97 & -0.39 & -6.03 & & 0.97 & 1.61 & 2.46 & 4.1 & 3.59 \\
\hline & Trend & no & & & no & no & yes & & no & no & yes & yes & yes \\
\hline & Direction & --- & & & --- & --- & $\downarrow$ & & --- & --- & $\uparrow$ & $\uparrow$ & $\uparrow$ \\
\hline & Date & --- & & & --- & --- & 1988 & & --- & --- & 1995 & 1992 & 1990 \\
\hline \multirow{4}{*}{$\begin{array}{l}\frac{5}{5} \\
\frac{D}{0} \\
\text { 胥 }\end{array}$} & $\mathrm{u}(\mathrm{t})$ & 3.48 & & & & -2.87 & -4.81 & & & 3.96 & 4.54 & 4.95 & 3.96 \\
\hline & Trend & yes & & & & yes & yes & & & yes & yes & yes & yes \\
\hline & Direction & $\uparrow$ & & & & $\downarrow$ & $\downarrow$ & & & $\uparrow$ & $\uparrow$ & $\uparrow$ & $\uparrow$ \\
\hline & Date & 2012 & & & & 1988 & 1988 & & & 2007 & 2007 & 2007 & 2007 \\
\hline \multirow{4}{*}{ 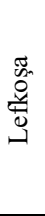 } & $\mathrm{u}(\mathrm{t})$ & -0.12 & 3.25 & & & & & & -0.56 & 1.07 & 1.24 & 3.38 & -0.63 \\
\hline & Trend & no & yes & & & & & & no & no & no & yes & no \\
\hline & Direction & --- & $\uparrow$ & & & & & & --- & --- & --- & $\uparrow$ & --- \\
\hline & Date & --- & 1997 & & & & & & --- & --- & --- & 2001 & --- \\
\hline \multirow{4}{*}{ 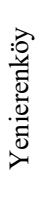 } & $\mathrm{u}(\mathrm{t})$ & 1.89 & & & 0.42 & -1.34 & -3.79 & & 0.39 & 1.82 & 1.24 & 1.65 & 0.59 \\
\hline & Trend & no & & & no & no & yes & & no & no & no & no & no \\
\hline & Direction & -- & & & --- & --- & $\downarrow$ & & -- & --- & -- & -- & --- \\
\hline & Date & --- & & & --- & --- & 1987 & & --- & --- & --- & --- & --- \\
\hline
\end{tabular}



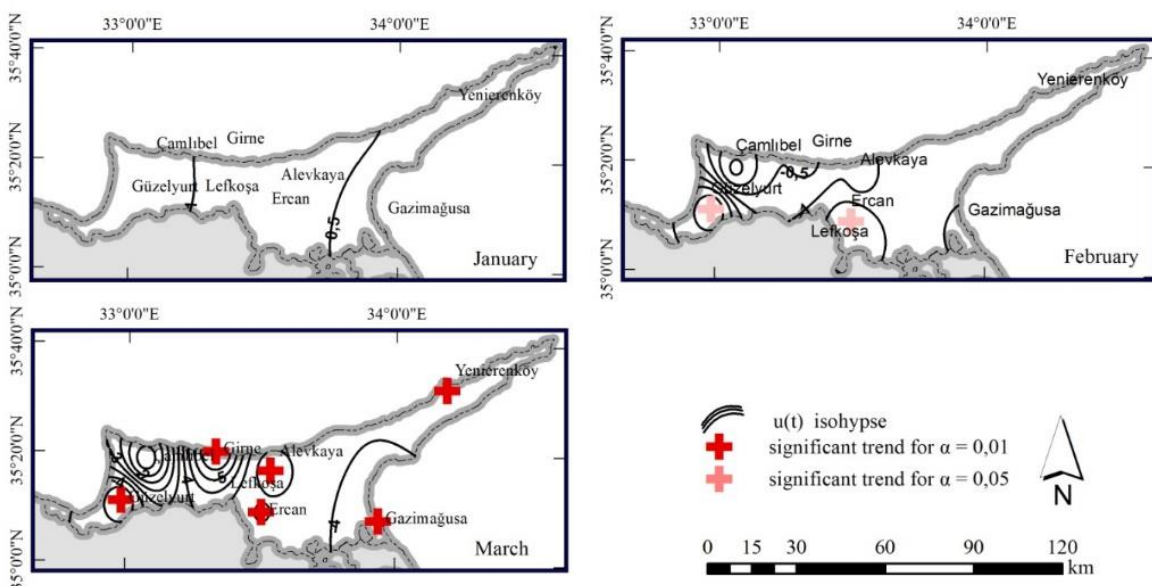

Figure 4. Spatial distribution of Mann-Kendall rank correlation statistics for the months with water surplus (1986-2016)
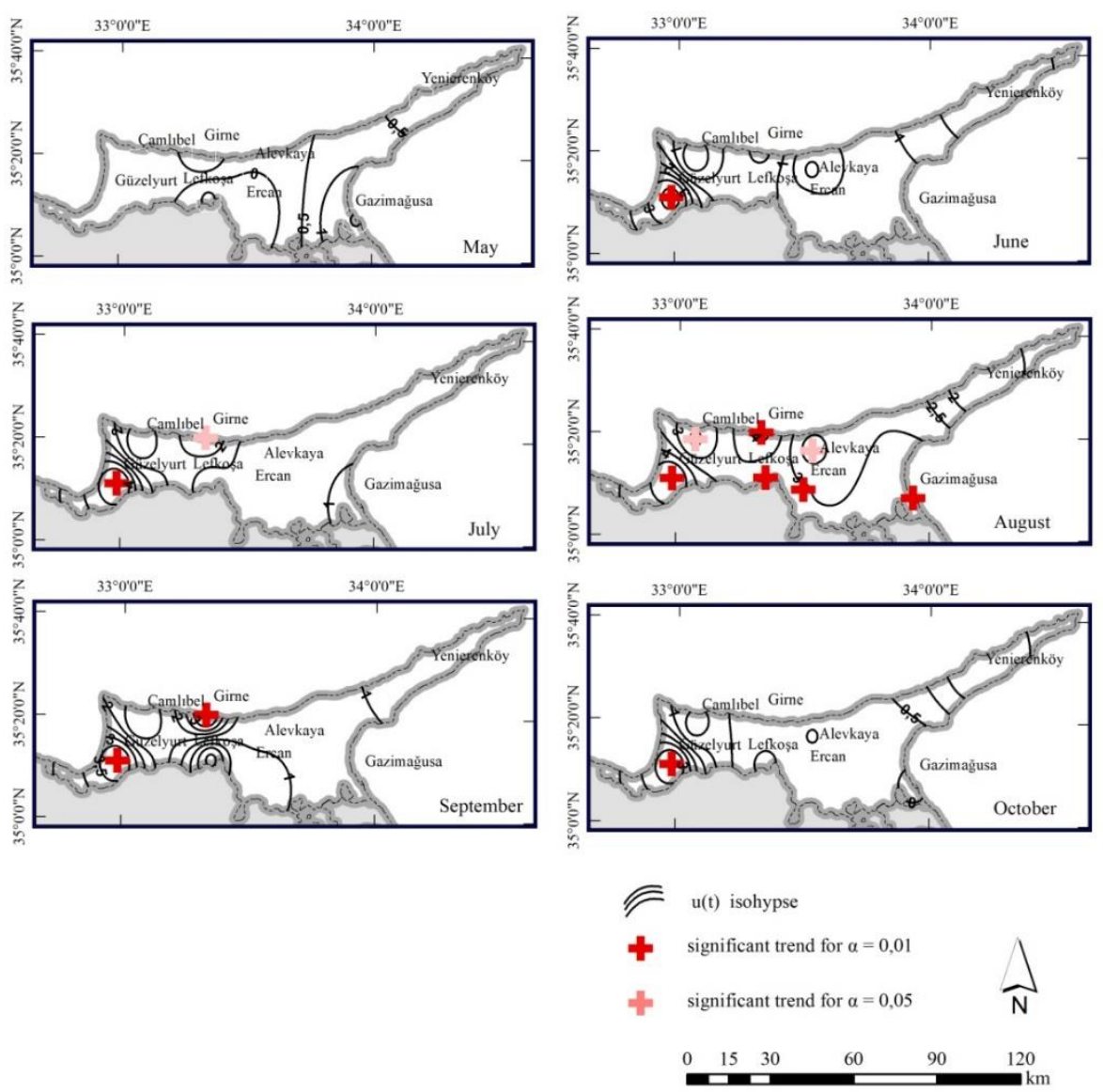

Figure 5. Spatial distribution of Mann-Kendall rank correlation statistics for the months with water deficit (1986-2016) 


\section{Conclusions}

The study findings show a water deficit in a large period of the year throughout Northern Cyprus. The amount and duration of the water deficit are not homogeneous throughout Northern Cyprus. The amount and duration of water deficit exhibit differences, especially between the northern and inner parts. It was determined that, in the inner parts of the TRNC, water deficit occurred in 53\% of the water year (the highest 58\%, the lowest 50\%), and the amount of water deficit was $752 \mathrm{~mm} /$ year (the highest $760 \mathrm{~mm} /$ year, the lowest $744 \mathrm{~mm} /$ year). The duration of the water deficit increases in the northwestsoutheast direction between the Güzelyurt (Morfou) and Gazimağusa (Famagusta) gulfs. The amount of water deficit reaches its highest level in the Middle Mesaoria Plain. It was determined that, in the northern parts of the TRNC, water deficit occurred in $47 \%$ of the water ear (the highest $50 \%$, the lowest 42\%), and the amount of water deficit was $614 \mathrm{~mm} /$ year (the highest $760 \mathrm{~mm} /$ year, the lowest 430 $\mathrm{mm} / \mathrm{year}$ ). The duration of the water deficit increases in the west-east direction between the Güzelyurt Gulf and Karpas Peninsula. In the north of the TRNC, the amount of water deficit reaches its highest level in Girne (Kyrenia) and its immediate surroundings.

The trend analyses revealed statistically significant trends in both water surplus and water deficit across Northern Cyprus. While significant trends observed in months with water surplus indicated a decrease in water surplus, significant trends observed in months with water deficit pointed to an increase in water deficit. During the thirty-one-year uninterrupted period, a significant decrease trend was observed in the number of months with water surplus on an annual scale. It is predicted that there will be an increase in the amount and duration of water deficit throughout Northern Cyprus with the continuation of the trends.

\section{Referanslar/References}

Allen, M.R., Dube, O.P., Solecki, W., Aragón-Durand, F., Cramer, W., Humphreys, S., Kainuma, M., Kala, J., Mahowald, N., Mulugetta, Y., Perez, R., Wairiu, M., Zickfeld, K. (2018). Framing and Context. In Masson-Delmotte, V., Zhai, P., Pörtner, H.O., Roberts, D., Skea, J., Shukla, P.R., Pirani, A. Moufouma-Okia, W., Péan, C., Pidcock, R., Connors, S.,Matthews, J.B.R., Chen, Y., Zhou, X., Gomis, M.I., Lonnoy, E., Maycock, T., Tignor M., Waterfield, T. (eds.), Global Warming of $1.5^{\circ} \mathrm{C}$. An IPCC Special Report on the impacts of global warming of $1.5^{\circ} \mathrm{C}$ above pre-industrial levels and related global greenhouse gas emission pathways, in the context of strengthening the global response to the threat of climate change, sustainable development, and efforts to eradicate poverty. (pp. 49-91). https:/www.ipcc.ch/site/assets/uploads/sites/2/2019/06/SR15_Full_Report_High_Res.pdf adresinden alınd1.

Bates, B.C., Kundzewicz, Z.W., Wu, S., Palutikof, J.P. (2008). Climate Change and Water. Technical paper of the intergovernmental panel on climate change (IPCC). Geneva: IPCC.

Benjamin N.N., Jacques, M., Jean, S.R. (2007). Groundwater recharge from rainfall in the southern border of Lake Chad in Cameroon, World Applied Sciences Journal, 2 (2), 125-131.

Blöschl, G., Hall, J., Viglione, A., Perdigão, R.A.P., Parajka, J., Merz, B., Lun, D., Arheimer, B., Aronica, G.T., Bilibashi, A., .... Živković, N. (2019). Changing climate both increases and decreases European river floods. Nature, 573, 108-111. doi: 10.1038/s41586-019-1495-6

Chahine, M.T. (1992). The hydrological cycle and its influence on climate. Nature, 359 (6394), 373-380. doi: $10.1038 / 359373 \mathrm{a} 0$

Chenoweth, J., Hadjinicolaou, P., Bruggeman, A., Lelieveld, J., Levin, Z., Lange, M. A., Xoplaki, E., Hadjikakou, M. (2011). Impact of climate change on the water resources of the eastern Mediterranean and Middle East region: Modeled 21st century changes and implications. Water Resources Research, 47 (6). doi: 10.1029/2010WR010269

Christofi, C., Bruggeman, A., Kuells, C., Constantinou, C. (2020). Hydrochemical evolution of groundwater in gabbro of the Troodos Fractured Aquifer. A comprehensive approach. Applied Geochemistry, $114 . \quad$ doi: 10.1016/j.apgeochem.2020.104524 
Caloiero, T., Caloiero, P., Frustaci, F. (2018). Long-term precipitation trend analysis in Europe and in the Mediterranean basin. Water and Environment Journal, 32 (3), 433-445. doi:10.1111/wej.12346

Cook, J., Nuccitelli, D., Green, S.A., Richardson, M., Winkler, B., Painting, R., Way, R., Jacobs, P., Skuce, A. (2013). Quantifying the consensus on anthropogenic global warming in the scientific literature. Environmental Research Letters, 8 (2). doi: 10.1088/1748-9326/8/2/024024

Crowley, T.J., North, G.R. (1988). Abrupt climate change and extinction events in earth history. Science, 240 (4855), 9961002. doi: $10.1126 /$ science. 240.4855 .996

Cuthbert, M.O., Gleeson, T., Moosdorf, N., Befus, K.M., Schneider, A., Hartmann, J., Lehner, B. (2019). Global patterns and dynamics of climate-groundwater interactions. Nature Climate Change, 9 (2), 137-141. doi: 10.1038/s41558-0180386-4

Danandeh Mehr, A., Sorman, A.U., Kahya, E., Hesami Afshar, M. (2020). Climate change impacts on meteorological drought using SPI and SPEI: case study of Ankara, Turkey. Hydrological Sciences Journal, 65 (2), 254-268. doi:10.1080/02626667.2019.1691218

Demircan, M., Çiçek, İ., Türkoğlu, N., Ekici, M., Arabacı, H., Akçakaya, A. (2015). Ortalama sıcaklıklardaki türdeşlik kırılmalarının iklim göstergeleriyle ilişkisi. VII. Uluslararası Katılımlı Atmosfer Bilimleri Sempozyumu 28-30 Nisan 2015, Bildiriler Kitabı içinde (s. 605-614). İstanbul.

Donat, M.G., Lowry, A.L., Alexander, L.V., O’Gorman, P.A., Maher, N. (2016). More extreme precipitation in the world's dry and wet regions. Nature Climate Change, 6 (5), 508-513. doi:10.1038/nclimate2941

Ergil, M.E. (2000). The salination problem of the Guzelyurt aquifer, Cyprus. Water Research, 34 (4), 1201-1214. doi: $10.1016 /$ S0043-1354(99)00253-5

Fan, Y., Li, H., Miguez-Macho, G. (2013). Global patterns of groundwater table depth. Science, 339, 940-943. doi: $10.1126 /$ science. 1229881

Fetter, C.W. (1994). Applied Hydrogeology. New Jersey: Prentice-Hall.

Gamgam, H., Altunkaynak, B. (2013). Parametrik Olmayan Yöntemler. Ankara: Şeçkin Yayıncılık.

Giannakopoulos, C., Hadjinicolaou, P., Kostopoulou, E., Varotsos, K.V., Zerefos, C. (2010). Precipitation and temperature regime over Cyprus as a result of global climate change. Advances in Geosciences, 23, 17-24. doi:10.5194/adgeo-2317-2010. doi: 10.5194/adgeo-23-17-2010

Goosse, H., Barriat, P.Y., Lefebvre, W., Loutre, M.F., Zunz, V. (2010). Brief History of Climate: Causes and Mechanisms. In Introduction to Climate Dynamics and Climate Modelling. (pp. 109-144). New York: Cambridge University Press.

Grinevskiy, S.O., Pozdniakov, S.P., Dedulina, E.A. (2021). Regional-scale model analysis of climate changes impact on the water budget of the critical zone and groundwater recharge in the European part of Russia. Water, 13 (4), 428. doi: $10.3390 / \mathrm{w} 13040428$

Gönençgil, B., Çavuş, E. (2006). Kuzey Kıbrıs Türk Cumhuriyeti’nin İklimi. İstanbul: Elçi Yayıncılık.

Gürsoy, S.İ., Jacques, P.J., (2014). Water security in the Middle East and North African region. Journal of Environmental Studies and Sciences, 4 (4), 310-314. doi: 10.1007/s13412-014-0180-1

Hagemann, S., Chen, C., Clark, D.B., Folwell, S., Gosling, S.N., Haddeland, I., Hanasaki, N., Heinke, J., Ludwig, F., Voss, F., Wiltshire, A.J. (2013). Climate change impact on available water resources obtained using multiple global climate and hydrology models. Earth System Dynamics, 4 (1), 129-144. doi:10.5194/esd-4-129-2013

Hosseinzadehtalaei, P., Tabari, H., Willems, P. (2020). Climate change impact on short-duration extreme precipitation and intensity-duration-frequency curves over Europe. Journal of Hydrology, 590. doi: 10.1016/j.jhydrol.2020.125932

Huntington T.G. (2006). Evidence for intensification of the global water cycle: Review and synthesis. Journal of Hydrology, 319 (1-4), 83-95. doi: 10.1016/j.jhydrol.2005.07.003

Hutjes, R.W.A., Kabat, P., Running, S.W., Shuttleworth, W.J., Field, C., Bass, B., ... Vörösmarty, C.J. (1998). Biospheric aspects of the hydrological cycle. Journal of Hydrology, 212, 1-21. doi: 10.1016/S0022-1694(98)00255-8

IPCC, (2007). Climate Change 2007: Synthesis Report. Contribution of Working Groups I, II and III to the Fourth Assessment Report of the Intergovernmental Panel on Climate Change [Core Writing Theme], Pachauri, R.K., Reisinger, A. (eds). Geneva: IPCC

IPCC, (2014). Climate Change 2014: Synthesis Report. Contribution of Working Groups I, II and III to the Fifth Assessment Report of the Intergovernmental Panel on Climate Change [Core Writing Team], Pachauri, R.K., Meyer, L.A. (eds.). Geneva: IPCC 
Iglesias, A., Garrote, L., Flores, F., Moneo, M. (2007). Challenges to manage the risk of water scarcity and climate change in the Mediterranean. Water Resources Management, 21 (5), 775-788. doi:10.1007/s11269-006-9111-6

Jehanzaib, M., Shah, S.A., Yoo, J., Kim, T.W. (2020). Investigating the impacts of climate change and human activities on hydrological drought using non-stationary approaches. Journal of Hydrology, 588, 125052. doi: 10.1016/j.jhydrol.2020.125052

Katsanos, D., Retalis, A., Michaelides, S. (2016). Validation of a high-resolution precipitation database (CHIRPS) over Cyprus for a 30-year period. Atmospheric Research, 169, 459-464. doi: 10.1016/j.atmosres.2015.05.015

Katsanos, D., Retalis, A., Tymvios, F., Michaelides, S. (2017). Study of Precipitation Extremes in Cyprus. In Karacostas, T., Bais, A., Nastos, P.T. (eds.), Perspectives on Atmospheric Sciences. (pp. 559-564). Cham: Springer.

Katsanos, D., Retalis, A., Tymvios, F., Michaelides, S. (2018). Study of extreme wet and dry periods in Cyprus using climatic indices. Atmospheric Research, 208, 88-93. doi: 10.1016/j.atmosres.2017.09.002

Kelley, C., Ting, M., Seager, R., Kushnir, Y. (2012). Mediterranean precipitation climatology, seasonal cycle, and trend as simulated by CMIP5. Geophysical Research Letters, 39 (21). doi: 10.1029/2012GL053416

Koday, Z. (1995). Kuzey Kıbrıs Türk Cumhuriyeti Devleti'nin coğrafi özellikleri. Atatürk Üniversitesi Türkiyat Araştırmaları Enstitüsü Dergisi, (2). 17-45.

Kundzewicz, Z.W. (2008). Climate change impacts on the hydrological cycle. Ecohydrology \& Hydrobiology, 8 (2-4), 195203. doi: 10.2478/v10104-009-0015-y

Kutoğlu, S. (2010). Kuzey Kıbrıs Türk Cumhuriyeti'nin jeomorfolojik ve uygulamalı jeomorfolojik etüdü. İstanbul Üniversitesi, Sosyal Bilimler Enstitüsü, Yayımlanmamış Doktora Tezi, İstanbul. https://tez.yok.gov.tr/UlusalTezMerkezi adresinden edinilmiştir.

Lelieveld, J., Hadjinicolaou, P., Kostopoulou, E., Chenoweth, J., El Maayar, M., Giannakopoulos, C., Hannides, C., Lange, M. A., Tanarhte, M., Tyrlis, E., Xoplaki, E. (2012). Climate change and impacts in the Eastern Mediterranean and the Middle East. Climatic Change, 114 (3), 667-687. doi: 10.1007/s10584-012-0418-4

Lionello, P., Abrantes, F., Gacic, M., Planton, S., Trigo, R., Ulbrich, U. (2014). The climate of the Mediterranean region: research progress and climate change impacts. Regional Environmental Change, 14, 1679-1684. doi:10.1007/s10113014-0666-0

Maden, T.E. (2013). Havzalar arası su transferinde büyük adım: KKTC İçme Suyu Temin projesi. Ortadoğu Analiz, 5 (50), $102-111$.

Madsen, H., Lawrence, D., Lang, M., Martinkova, M., Kjeldsen, T.R. (2014). Review of trend analysis and climate change projections of extreme precipitation and floods in Europe. Journal of Hydrology, 519, 3634-3650. doi: 10.1016/j.jhydrol.2014.11.003

Maibach, E., Myers, T., Leiserowitz, A. (2014). Climate scientists need to set the record straight: There is a scientific consensus that human-caused climate change is happening. Earth's Future, 2 (5), 295-298. doi:10.1002/2013EF000226

McDonald, R.I., Green, P., Balk, D., Fekete, B.M., Revenga, C., Todd, M., Montgomery, M. (2011). Urban growth, climate change, and freshwater availability. Proceedings of the National Academy of Sciences of the United States of America, 108 (15), 6312-6317. doi: 10.1073/pnas.1011615108

Önol, B., Ünal, Y.S. (2014). Assessment of climate change simulations over climate zones of Turkey. Regional Environmental Change, 14 (5), 1921-1935. doi: 10.1007/s10113-012-0335-0

Öztürk, K. (2002). Küresel iklim değişikliği ve Türkiye’ye olası etkileri. Gazi Üniversitesi Gazi Eğitim Fakültesi Dergisi, 22 (1), 47-65.

Öztürk, M.Z. (2013). Kuzey Kıbrıs kıyılarının (Koruçam burnu-Zafer burnu-Zeytin burnu arasının) kuvaterner jeomorfolojisi. Çanakkale Onsekiz Mart Üniversitesi, Sosyal Bilimler Enstitüsü, Yayımlanmamış Doktora Tezi, Çanakkale. https://tez.yok.gov.tr/UlusalTezMerkezi adresinden edinilmiştir.

Öztürk, T., Ceber, Z.P., Türkeş, M., Kurnaz, M.L. (2015). Projections of climate change in the Mediterranean Basin by using downscaled global climate model outputs. International Journal of Climatology, 35 (14), 4276-4292. doi: $10.1002 /$ joc. 4285

Padrón, R.S., Gudmundsson, L., Decharme, B., Ducharne, A., Lawrence, D.M., Mao, J., ... Seneviratne, S.I. (2020). Observed changes in dry-season water availability attributed to human-induced climate change. Nature Geoscience, 13 (7), 477 481. doi: 10.1038/s41561-020-0594-1

Payab, A.H., Türker, U. (2018). Analyzing temporal-spatial characteristics of drought events in the northern part of Cyprus. Environment, Development and Sustainability, 20 (4), 1553-1574. doi: 10.1007/s10668-017-9953-5 
Philandras, C.M., Nastos, P.T., Kapsomenakis, J., Douvis, K.C., Tselioudis, G., Zerefos, C.S. (2011). Long term precipitation trends and variability within the Mediterranean region. Natural Hazards and Earth System Sciences, 11 (12), 32353250. doi: 10.5194/nhess-11-3235-2011

Phillips Agboola, O., Egelioglu, F. (2012). Water scarcity in North Cyprus and solar desalination research: a review. Desalination and Water Treatment, 43 (1- 3), 29-42. doi: 10.1080/19443994.2012.672195

Poschlod, B., Zscheischler, J., Sillmann, J., Wood, R.R., Ludwig, R. (2020). Climate change effects on hydrometeorological compound events over southern Norway. Weather and Climate Extremes, 28, 100253. doi: $10.1016 /$ j.wace. 2020.100253

Price, C., Michaelides, S., Pashiardis, S., Alpert, P. (1999). Long term changes in diurnal temperature range in Cyprus. Atmospheric Research, 51 (2), 85-98. doi:10.1016/S0169-8095(99)00022-8

Sağlamoğlu, A., Irvem, A. (2020). Regional drought analysis for the eastern Mediterranean region of Turkey using run and SPI method. Fresenius Environmental Bulletin, 26, 1256-1262.

Sneyers, R. (1990). On the statistical analysis of series of observations. World Meteorological Organization (WMO) Technical Note 43. Geneva: WMO.

Sousa, P.M., Trigo, R.M., Aizpurua, P., Nieto, R., Gimeno, L., Garcia-Herrera, R. (2011). Trends and extremes of drought indices throughout the 20th century in the Mediterranean. Natural Hazards and Earth System Sciences, 11 (1), 33-51. doi:10.5194/nhess-11-33-2011

Şenol, C. (2020). Kuzey Kıbrıs Türk Cumhuriyeti’nin hidrografik yapısı, su sorunu ve çözüm önerileri. Kıbrıs Araștırmaları Dergisi, 21 (45), 77-98.

Thornthwaite, C.W. (1948). An Approach Toward a Rational Classification of Climate, Geographical Review, 38, 55-94.

Türkeş, M. (1996). Spatial and temporal analysis of annual rainfall variations in Turkey. International Journal of Climatology, 16 (9), 1057-1076. doi: 10.1002/(SICI)1097-0088(199609)16:9<1057::AID-JOC75>3.0.CO;2-D

Türkeş, M. (2003). Spatial and temporal variations in precipitation and aridity index series of Turkey. In Bolle, H.J. (ed.), Mediterranean climate - variability and trends (pp 181-213). Regional Climate Studies., Heidelberg: Springer.

Türkeş, M. (2008). Küresel iklim değişikliği nedir? Temel kavramlar, nedenleri, gözlenen ve öngörülen değişiklikler. İklim Değişikliği ve Çevre, 1 (1), 26-37.

Türkeş, M. (2010). Klimatoloji ve Meteoroloji. İstanbul: Kriter Yayınevi.

Türkeş, M. (2012). Türkiye'de gözlenen ve öngörülen iklim değişikliği, kuraklık ve çölleşme. Ankara Üniversitesi Çevrebilimleri Dergisi, 4 (2), 1-32. doi:10.1501/Csaum_0000000063

Türkeş, M. (2020). Climate and Drought in Turkey. In Harmancioglu N., Altinbilek, D. (eds.), Water Resources of Turkey. (pp. 85-125), World Water Resources vol 2., Cham: Springer.

Türkeş, M., Sarış, F. (2007). Trends and changes of mean, maximum, minimum temperature and precipitation series in Northern Cyprus. Journal of the Black Sea/Mediterranean Environment, 13, 281-305.

Türkeş, M., Sümer, U.M., Demir, İ. (2002). Re-evaluation of trends and changes in mean, maximum and minimum temperatures of Turkey for the period 1929-1999, International Journal of Climatology, 22 (8), 947-977. doi:10.1002/joc.777

Türkeş, M., Koç, T., Sariş, F. (2009). Spatiotemporal variability of precipitation total series over Turkey. International Journal of Climatology. 29 (8), 1056-1074. doi: 10.1002/joc.1768

Yıldız, D. (2003). Akdeniz Havzası'nda Su Sorunları ve Türkiye. Ankara: Türk Mühendis ve Mimar Odaları Birliği (TMMOB) İnşaat Mühendisleri Odası (IMO) Ankara Şubesi.

Yılmaz, E. (2020). Kuzey Kıbrıs Türk Cumhuriyeti'ne su temin projelerinin hidropolitik açıdan değerlendirilmesi. Çankırı Karatekin Üniversitesi, Sosyal Bilimler Enstitüsü, Yayımlanmamış Yüksek Lisans Tezi, Çankırı. https://tez.yok.gov.tr/Ulusal Tez Merkezi adresinden edinilmiştir.

Zittis, G., Bruggeman, A., Camera, C. (2020). 21st century projections of extreme precipitation indicators for Cyprus. Atmosphere, 11 (4), 343. doi:10.3390/atmos11040343

Zikos, D., Sorman, A.H., Lau, M. (2015). Beyond water security: Asecuritisation and identity in Cyprus. International Environmental Agreements: Politics, Law and Economics, 15 (3), 309-326. doi: 10.1007/s10784-015-9280-y 